\title{
Effect of Nozzle Geometry on Jet Noise Reduction Using Fan Flow Deflectors
}

\author{
Dimitri Papamoschou* and Rebecca S. Shupe ${ }^{\dagger}$ \\ University of California, Irvine, Irvine, CA, 92697-3975
}

\begin{abstract}
We examine the effect of baseline nozzle shape on the ability of fan flow deflectors to reduce downward-emitted turbulent mixing noise of coaxial jets simulating the exhaust condition of a turbofan engine. Several deflector concepts were tested on a nozzle with parallel exit flow lines and a nozzle with convergent flow lines. In every comparison the nozzle with convergent flow lines produced superior acoustic benefit. Mean flow measurements indicate that the convergent lines help the deflectors reduce velocity gradients uniformly on the underside of the jet. In contrast, the parallel flow lines contributed to reduction in gradients in a narrow direction, with occasional increase of gradients in other directions that influence emission towards the ground.
\end{abstract}

\section{Nomenclature}

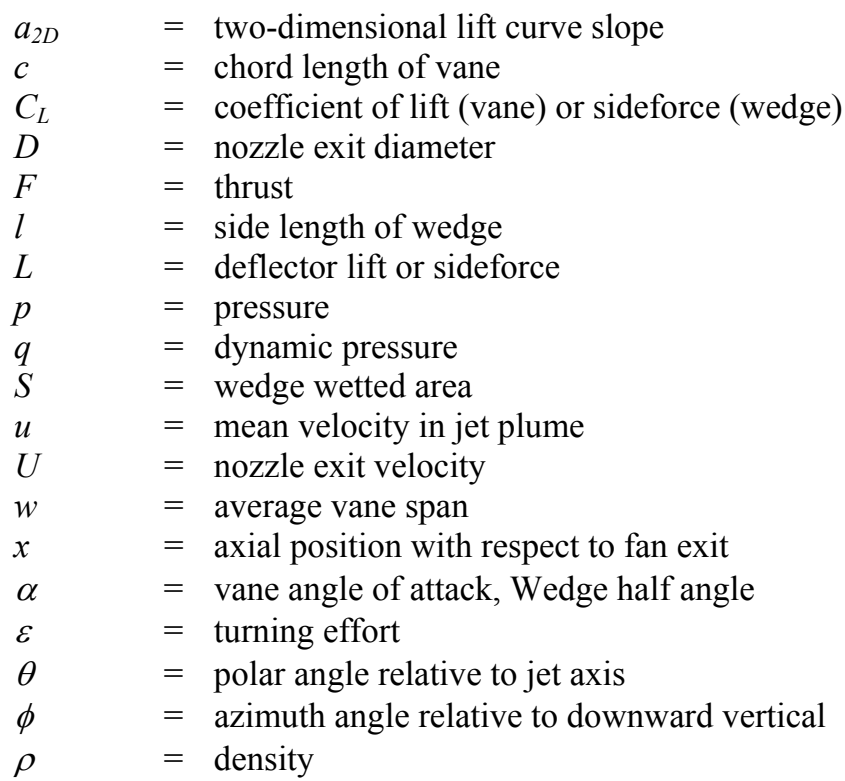

Subscripts

$\begin{array}{lll}f & =\text { fan } \\ p & =\text { primary (core) stream } \\ l e & =\text { leading edge of vane } \\ s & =\text { secondary (bypass) stream } \\ t e & =\text { trailing edge of vane } \\ 0 & =\text { total (stagnation), fixed axial location }\end{array}$

\footnotetext{
* Professor, Department of Mechanical and Aerospace Engineering, 4200 Engineering Gateway, Irvine, CA 926973975, AIAA Associate Fellow.

${ }^{\dagger}$ Graduate Student Researcher, Department of Mechanical and Aerospace Engineering, 4200 Engineering Gateway, Irvine, CA 92697-3975, AIAA Member. 


\section{Introduction}

$\mathrm{T}$ HE focus of the current study is the effect of baseline nozzle shape on the noise suppression capability of the fan flow deflection (FFD) method. Several studies using conventional and realistic coaxial nozzles have shown the significant potential of FFD to reduce jet mixing noise, particularly in the direction of peak emission. ${ }^{1,2}$ The working principle of FFD is reduction of the convective Mach number of turbulent eddies that generate intense downward and sideward sound radiation. In a coaxial separate-flow turbofan engine this is achieved by tilting in the general downward direction, by a few degrees, the bypass (secondary) plume relative to the core (primary) plume. Mean flow surveys show that the misalignment of the two flows causes a thick, low-speed secondary core on the underside of the high-speed primary flow, especially in the region near the end of the primary potential core which contains the strongest noise sources. The secondary core reduces the convective Mach number of the primary eddies, thus hindering their ability to generate sound that travels to the downward acoustic far field. ${ }^{1}$ Tilting of the bypass stream is possible by means of fixed or variable deflectors installed near the exit of the bypass duct. Figure 1 depicts the general concept.

Two types of deflectors have been investigated so far: airfoil-shaped vanes, mounted at various azimuth angles, and a wedge-shaped deflector located at the top of the nozzle. Both devices can be internal or external to the bypass duct, although for commercial applications it is strongly preferred that the vanes be internal to avoid shock losses. The deflectors have been tested in "classic" laboratory nozzles with parallel exit flow lines and in "realistic" nozzles with convergent flow lines characteristic of turbofan engines. Vanes provide noticeable noise reduction for both types of nozzles, although noise reduction in the realistic nozzle was superior to that in the classic nozzle ${ }^{2}$. However, tests of an internal wedge-type deflector showed practically no noise benefit in a classic nozzle, while there was appreciable benefit in a realistic nozzle. The "discrepancy" between classic and realistic nozzles was observed in small-scale experiments at U.C. Irvine and in larger-scale experiments at NASA Glenn Research Center $^{3}$. It thus became evident that the shape of the baseline nozzle plays a role on the efficacy of the FFD method, and that a systematic study of FFD in nozzles of varying shape was necessary for further understanding of the technique and for design considerations. This is the motivation for this paper. We present acoustic and mean-flow results for a variety of fan flow deflectors tested in a nozzle with parallel flow lines and a nozzle with convergent flow lines.

\section{Experimental Setup}

Experiments covered two nozzle geometries, four FFD configurations, and two types of comparisons: equal deflector turning effort and equal deflector geometry. Comparisons at equal turning effort, to be defined below, were desirable to distill the effect of nozzle geometry from the effect of deflection force.

\section{A. Nozzles}

The UCI classic nozzle has parallel exit streamlines and an inner nozzle protrusion of $9.5 \mathrm{~mm}$. The UCI 3BB nozzle is a scaled-down version of the bypass-ratio 5 baseline separate-flow nozzle used at NASA Glenn Research Center. ${ }^{4}$ It has convergent exit flow lines and a geometry that is representative of actual separate-flow turbofan engines. The nozzle coordinates are shown Figs. 4-7 along with the deflectors, and the baseline nozzles are shown in Fig. 8. Exit conditions are listed in Tables 1 and 2. Both nozzles were constructed with rapid-prototyping methods.

As far as deflector aerodynamics is concerned, the principal difference between the two nozzles is in the internal Mach number distribution. In the nozzle with rapidly convergent exit streamlines, the Mach number decreases quickly moving upstream of the fan exit, while in the nozzle with parallel streamlines, the Mach number changes slowly in the vicinity of the nozzle exit, Fig. 9.

\section{B. Deflectors}

The deflector parameters are similar to those used in earlier exploratory studies. ${ }^{1,2}$ They do not represent optimal design configurations. Four configurations were tested: internal wedge $\left(\mathrm{W}_{\mathrm{i}}\right)$, external wedge $\left(\mathrm{W}_{\mathrm{e}}\right)$, a single pair of internal vanes $(2 \mathrm{~V})$, and two pairs of internal vanes $(4 \mathrm{~V})$. Their geometries are shown in Figs. 4-7. Tables 3 and 4 list the deflector parameters.

It was desired to perform some comparisons between the classic and 3BB nozzles on an "equal turning effort" basis, meaning that the deflector force, normalized by the thrust of the bypass stream, is approximately the same in both nozzles. The turning effort can be seen as an overall deflection angle based on the force of the deflectors alone (i.e., without considering any additional forces created by the nozzle surface). Its definition is 


$$
\varepsilon=\frac{1}{F_{s}} \sum_{i=1}^{N} L_{i},
$$

where $L_{\mathrm{i}}$ is the lift, or sideforce, generated by each deflector and $N$ is the total number of deflectors. Both nozzles produced approximately the same secondary (bypass) thrust $F_{s}$. Currently, there is specific information on the sideforce generated by the wedge deflector. However, for the external wedge $\left(\mathrm{W}_{\mathrm{e}}\right)$ one can reasonably assume

$$
L_{W e}=C_{L}(\alpha) q_{s} S,
$$

where $C_{L}$ is a sideforce coefficient that should depend only on the wedge half-angle $\alpha ; q_{s}$ is the dynamic pressure at the nozzle exit; and $S$ is the wetted area of the wedge. Given that $q_{s}$ is the same for both nozzles, equal sideforce is achieved by wedges of equal half-angle and wetted area.

For internal vanes, a computational study showed that the lift coefficient of the vane airfoil (in that case a NACA 0012 section) matches the lift coefficient of the same airfoil in external flow if the reference conditions are those at the axial position of the leading edge of the vane, in the absence of the vane. ${ }^{6}$ With this selection of reference conditions, the lift coefficient of the vane airfoil is given by the familiar relation

$$
C_{L}=a_{2 D} \alpha,
$$

where $a_{2 D}$ is the two-dimensional lift curve slope (typically $0.11 \mathrm{deg}^{-1}$ ). Therefore, the vane lift is

$$
L_{V}=a_{2 D} \alpha q_{l e} c w,
$$

where $w$ is the average vane span. Equations 2 and 4 provided guidance for the design of deflectors that would allow comparisons at equal turning effort $\varepsilon$. Other comparisons were performed on an equal chord length basis. Details of the deflector designs follow.

Both external wedges $\left(\mathrm{W}_{\mathrm{e}}\right)$ had the same half-angle and were mounted at the top of the two nozzles $\left(\phi=180^{\circ}\right)$. It was thus assumed that the sideforce coefficients were the same. In order for the sideward forces imparted by the wedges to be matched, the wetted area of the wedges must be consistent between nozzles. Since the fan duct thickness is $3.9 \mathrm{~mm}$ for the classic nozzle and $3.1 \mathrm{~mm}$ for the UCI 3BB nozzle, it was thought that the wedge side lengths could be changed to match the wetted areas. This was not necessary, however, since the wetted areas were approximately the same. The wetted area was estimated as follows: along the free surface, as the flow passes over the wedge, the pressure is ambient. Assuming isentropic flow, the Mach number remains constant. This means that the temperature is also constant along the free surface. From the continuity equation, the area filled by the flow must be constant, but the surface of the 3BB nozzle is conical in shape and the streamlines do not remain parallel to the surface. A simple calculation showed that the wetted area of the UCI 3BB wedge for a wedge with a half angle of $\alpha$ $=18^{\circ}$ and side length of $l=10 \mathrm{~mm}$ is $37 \mathrm{~mm}^{2}$. The wetted area for a wedge with the same half angle and side length on the classic nozzle is rectangular because the flow lines are parallel, and it is $39 \mathrm{~mm}^{2}$. The comparison was performed using the same external wedge $\left(\mathrm{W}_{\mathrm{e}}\right)$ in both nozzles. The wedge deflectors were cut from 4.5 -mm-thick nylon sheet. The wedge cross-section was rectangular, and the height was $4.5 \mathrm{~mm}$.

The internal wedge problem is more complicated because of the favorable pressure gradient inside the fan duct. This comparison was also performed using the same internal wedge $\left(\mathrm{W}_{\mathrm{i}}\right)$ in both nozzles. Without estimating the sideforce, we note that it will be larger in the classic nozzle than in the 3BB nozzle because of the larger average dynamic pressure in the classic nozzle.

The parameters for the vane deflectors include: chord length, $c$; axial location of trailing edge relative to the exit of the fan duct, $x_{t e}$; angle of attack, $\alpha$; and azimuth angle, $\phi$. The parameters selected for the current experiments are listed in Tables 3 and 4, and the vane configurations are shown in Figs. 6 and 7. Two types of comparisons between the classic and 3BB nozzles are performed: equal turning effort $\varepsilon$; and equal chord length. Figure 9 overlays the placement of the vanes with the dynamic pressure distribution in each nozzle. In the 3BB nozzle, the Mach number and dynamic pressure increase rapidly near the fan exit because of the rapidly converging duct. As a consequence, at fixed axial position, the Mach number and dynamic pressure in the 3BB nozzle are smaller than those in the classic nozzle.

The trailing edges of all vanes were placed at the exit plane of the fan duct, $x_{\mathrm{te}}=0$, a choice necessitated by the constraints of this study and not an ideal placement from an optimal design point of view. In the first type of comparison, the lift force, calculated from Eq.4, was matched by reducing the chord length of the vanes in the classic nozzle to compensate for the larger dynamic pressure relative to the $3 \mathrm{BB}$ nozzle. In the second type of comparison, the chord length of the vanes in the classic nozzle matched the chord length of the vanes in the 3BB nozzle. The turning effort was estimated for both types of comparisons, and the values are provided in Tables 3 and 4. All the vanes were fabricated from thin $(0.36-\mathrm{mm})$ brass sheet. Electrical tape $(0.18-\mathrm{mm}$ thickness $)$ was wrapped around the vanes to produce a round leading edge. 


\section{Noise Measurement}

For acoustic simulation of hot jets, the nozzles were attached to the dual-stream apparatus, shown in Fig. 3a, and cold mixtures of helium and air are supplied to the primary (core) and secondary (bypass) nozzles. Helium-air mixtures have been shown to simulate reasonably well the acoustics of hot jets. ${ }^{7,8}$ The exit flow conditions, listed in Tables 1 and 2, matched the typical exit conditions of a turbofan engine with bypass ratio 4.8 at takeoff setting. The Reynolds number of the jet, based on fan diameter, was $0.6 \times 10^{6}$. For more information on the helium-air mixture matching method, the reader is referred to Ref. 8.

The microphone phased array consists of eight 3.2-mm condenser microphones (Bruel \& Kjaer, Model 4138) arranged on a circular arc centered at the vicinity of the nozzle exit. The polar aperture of the array is $30^{\circ}$ and the array radius was $1 \mathrm{~m}$. The angular spacing of the microphones is logarithmic. The entire array structure is rotated around its center to place the array at the desired polar angle. Positioning of the array is done remotely using a stepper motor. An electronic inclinometer displays the position of first microphone. The arrangement of the microphones inside the anechoic chamber, and the principal electronic components, are shown in Fig. 3c. The microphones were connected, in groups of four, to two amplifier/signal conditioners (Bruel \& Kjaer, Model 4138) with low-pass filter set at $300 \mathrm{~Hz}$ and high-pass filter set at $100 \mathrm{kHz}$. The four-channel output of each amplifier was sampled at $250 \mathrm{kHz}$ per channel by a multi-function data acquisition board (National Instruments PCI-6070E). Two such boards, one for each amplifier, were installed in a Pentium 4 personal computer. National Instruments LabView software was used to acquire the signals. Even though the array provides noise source location maps, in this study it was used only to survey the far-field sound emitted by the jets. Only the downward azimuthal direction was surveyed. The sound pressure level spectrum was corrected for actuator response, free-field correction, and atmospheric absorption. The overall sound pressure level (OASPL) was obtained by integrating the corrected spectrum. All acoustic data are referenced to a distance of $100 D_{f}$ from the nozzle exit.

\section{Mean Velocity Measurement}

For the mean velocity measurements, the nozzles were attached to the dual-stream apparatus, shown in Fig. 3a, and compressed air was supplied to both the primary (core) and secondary (bypass) nozzles at room temperature. The Reynolds number of the jet, based on fan diameter, was $0.4 \times 10^{6}$. The exit conditions are listed in Tables 1 and 2. Even though the velocities are lower than those of a realistic turbofan exhaust (used in the acoustic tests), the velocity ratio of 0.7 is representative of that in turbofan engines and matches the velocity ratio in the acoustics tests.

A Pitot rake, shown in Fig. 3b, was used to survey the total pressure in the jet plume. The rake consisted of five stainless steel tubes, each $70 \mathrm{~mm}$ long, supported by an airfoil-shaped holder. The tubes were mounted $10 \mathrm{~mm}$ apart and their inner diameter is $1.0 \mathrm{~mm}$. The rake was mounted on a carriage with motorized motion in the $y$-direction and manual positioning in the $x$ - and $z$-directions. The second-from the top probe is the reference probe, and it is initially positioned at the tip of the plug. The negative $y$-direction defines the direction of the ground $(\phi=0)$. The five probes of the rake were connected individually to five pressure transducers (Setra Model 207). The transducers were mounted on the traverse assembly in order to minimize the length of the tubing between each probe and transducer. This arrangement minimized the response time of the probe-transducer system to values low enough to resolve the sharp spatial gradients in Pitot pressure near the nozzle exit. The typical carriage speed was $10 \mathrm{~mm} / \mathrm{s}$, and the transducers were sampled each at 1000 samples per second by an analog-to-digital board. Each $y$ traverse resulted in 11000 samples. Mach number and velocity were computed from the Pitot pressure assuming constant total temperature (equal to the ambient temperature) and uniform static pressure.

For each axial $x$-location, the rake traversed the plume in the $y$-direction a total of four times. Each time, the rake was moved by a $z$-increment of $2.5 \mathrm{~mm}$, i.e., one fourth of the probe spacing. This resulted in $20 z$-locations being surveyed for each $x$. The survey resolution was $2.5 \mathrm{~mm}$ in $z$ and $1.0 \mathrm{~mm}$ in $y$. A total of $25 x$-locations were surveyed for each case, with $x / D_{f}$ spanning a distance of about 10 . The surveys assumed symmetry of the velocity field around the plane $z=0$. Therefore, the surveys resolved the region $z \geq 0$ and a small portion of the region $z<0$ near $z=0$. Velocity data from the latter region were used to determine the true plane of symmetry of $u$, which may differ slightly from the geometric plane $z=0$. The true plane of symmetry was then used in mirror-imaging the velocity data.

\section{Results}

Mean velocity and acoustic measurements were conducted for ten nozzle-deflector combinations. First, in Fig.10, we present the velocity results for the baseline classic and 3BB nozzles. Two types of isocontours are 
presented: the velocity on the $z=0$ plane, normalized by the primary fully-expanded velocity, $u(x, y, 0) / U_{\mathrm{p}}$; and the velocity on various $x=x_{0}$ planes, normalized by the local maximum velocity, $u\left(x_{0}, y, z\right) / u_{\max }\left(x_{0}\right)$. The same type of plots will be shown for the cases with deflectors. For the baseline nozzles, we observe near-perfect axisymmetry of the flow, indicating good alignment of the nozzles and the Pitot rake.

For the cases with deflectors, shown in Figs. 11-16, the following information is provided:

- Mean-velocity profiles, in the same format as Fig.10, with the $u\left(x_{0}, y, z\right) / u_{\max }\left(x_{0}\right)$ isocontours being compared with their respective baselines.

- Plots of $u\left(x_{\mathrm{p}}, y, z\right) / u_{\max }\left(x_{p}\right)$, where $x_{\mathrm{p}}$ denotes the axial location where the maximum velocity drops to $80 \%$ of the primary exit velocity. This is a short distance past the end of the primary potential core. $x_{\mathrm{p}}$ is thus an indicator of the extent of the noise source region, with reduced $x_{\mathrm{p}}$ indicating greater mixing and thus a shorter source region. Each plot is compared to the corresponding baseline plot.

- Overall sound pressure level (OASPL) versus polar angle from the jet axis, with comparisons to the corresponding baselines. OASPL reductions are listed in Tables 3 and 4.

- Far-field, narrowband sound pressure level (SPL) spectra in the direction of peak emission, with comparisons to the respective baselines.

In all the figures, the results for the classic and 3BB nozzles are presented on the left- and right-hand sides, respectively. All axial distances are scaled by the respective fan nozzle diameters $D_{\mathrm{f}}$.

The mean-velocity and acoustic results for the internal wedge (Wi) are shown in Fig.11. While there is no great difference in the $u(x, y, 0)$ contours between classic and 3BB nozzles (top of Fig. 11a), there are significant differences in the cross-sectional isocontours (bottom of Fig. 11a, and Fig. 11b). The internal wedge on the classic nozzle produces a heart-shaped plume section with deflection mostly sideward and some thinning of the low-speed region on the underside of the jet. In contrast, the internal wedge on the 3BB nozzle deflects flow downward and sideward, producing a pear-shaped contour that reduces velocity gradients not only downward but also in the sideline direction. The OASPL plots show that the internal wedge on the classic nozzle gives marginal noise reduction, about $1.5 \mathrm{~dB}$, only at very small polar angles, and no noise reduction (and some noise increase) for the rest of the arc. This is consistent with earlier acoustic measurements ${ }^{3}$. On the other hand, the internal wedge on the 3BB nozzle produces strong noise reduction in the direction of peak emission $(5.5 \mathrm{~dB})$ and appreciable OASPL reduction up to $\theta=70^{\circ}$. The spectra in the directions of peak emission, Fig. 11, confirm the superiority of the 3BB nozzle, which reduces noise level for all frequencies. For the classic nozzle, there is noise decrease at low frequencies but significant noise increase at high frequencies.

The trends for the external wedge (We), shown in Fig.12, are similar to those for the internal wedge discussed above. We note a small improvement in the OASPL of the classic nozzle at low polar angles, possibly because the low speed region on the underside of the jet (Fig. 12b) is not thinned as much as for the internal wedge (Fig. 11b); however, there is excess noise at large polar angles. The peak OASPL reduction for 3BB nozzle is slightly lower than for the internal wedge. The behavior of SPL in the direction of peak emission mirrors that observed for the internal wedge.

We now examine the case of a single pair of vanes (2V) compared at equal turning effort, Fig. 13. The vanes in the classic nozzle produce an oblong velocity cross-section with reduced gradients in the downward direction but sharper gradients in the sideline direction. The vanes in the 3BB nozzle generate velocity contours that are pearshaped (similar to those observed with the wedges) and increase the thickness of the low-speed layer in the downward and sideline directions. The differences in OASPL and SPL between classic and 3BB nozzles are quite dramatic. The classic nozzle reduces levels marginally only at small polar angles and increases levels at large polar angles. In contract, the 3BB nozzle gives a strong reduction in the direction of peak emission and appreciable noise reduction up to $\theta=60^{\circ}$. Importantly, there is no significant excess OASPL at larger polar angles. For the classic nozzle, the spectra in the direction of peak emission reduce only at low frequencies and increase at high frequencies. The peak-emission spectra in the 3BB nozzle decline for all measured frequencies.

Figure 14 compares the $2 \mathrm{~V}$ configuration between classic and $3 \mathrm{BB}$ nozzles, with the vanes having equal chord. Now the vanes of the classic nozzle produce a larger turning effort than the vanes of the 3BB nozzle. The only significant difference with Fig. 13 (equal turning effort) is that the velocity cross-section of the classic nozzle has some lateral "fattening" on the underside of the jet, a result of the complex aerodynamics of the flow. The apparent effect of this fattening on the OASPL is that the noise excess observed in the equal-turning-effort comparison (Fig. $12 \mathrm{~b}$ ) is somewhat reduced. Overall, the performance of the classic nozzle is still inferior to that of the 3BB nozzle.

In the equal-turning effort and equal-chord comparisons with two pairs of vanes (4V), shown Figs. 15 and 16, respectively, we observe the same general trends as in the $2 \mathrm{~V}$ comparisons. Noise reduction in the direction of peak emission is now more pronounced for the classic and 3BB nozzles, owing to the larger deflection of the flow. Still, 
the classic nozzle produces OASPL reduction only for angles very close to the jet axis, while the 3BB nozzle reduces OASPL up to about $\theta=60^{\circ}$. A larger turning effort in the classic nozzle (Fig. 16 vs. Fig. 15) produces some lateral motion of the air, which apparently mitigates excess noise at large polar angles. The peak-emission spectra in the 3BB nozzle reduce across all frequencies while in the classic nozzle there are crossovers at high frequency.

\section{Conclusions}

We have conducted an investigation of the effect of baseline nozzle shape on the acoustic performance of fan flow deflectors for turbofan noise suppression. A coaxial nozzle with parallel flow lines ("classic") and a realistic coaxial nozzle with convergent flow lines ("3BB") were compared. The deflectors comprised internal vanes and internal and external wedges. Some comparisons were done at equal deflector turning effort while others were done at equal deflector geometry. The study consisted of mean-velocity measurements and far-field acoustic surveys in the downward direction. For all types of comparisons and all deflector arrangements, the 3BB nozzle produced superior acoustic performance. Importantly, the results shed more light on the desired shape of the mean flow field for effective noise suppression. The following general observations can be inferred from the results:

- A wedge-type deflector in a nozzle with parallel flow lines pushes flow mainly in the sideward direction and can thin the low-speed layer on the underside of the jet. This works contrary to the desired effect of fan flow deflection and gives marginal noise reduction and even noise increase.

- A nozzle with convergent flow lines helps the wedge-type deflector displace fluid downward and in the sideline direction. Velocity gradients are reduced for most of the downward perimeter of the jet. Appreciable noise reduction is achieved for a large range of polar angles.

- With internal vanes, the nozzle with parallel flow lines produces an oblong velocity cross section with reduced gradients in the strictly-downward direction and enhanced gradients in the sideline direction. An apparent consequence of this is that noise reduction is confined to small polar angles and noise excess is often observed at large polar angles.

- Internal vanes in a nozzle with convergent flow lines displace flow downward and in the sideline direction, hence reducing gradients in those directions. Noise reduction in the direction of peak emission is substantial and across all measured frequencies. OASPL benefit is observed for polar angles up to 60 deg. with respect to the jet axis.

- As a general conclusion, the best noise reduction is attained when a low-speed layer is concentrated uniformly on the underside of the jet. The resulting velocity cross-section is "pear-shaped."

\section{Acknowledgment}

The support by NASA Glenn Research Center is gratefully acknowledged (Grant NAG-3-2345 monitored by Dr. Khairul B. Zaman and Dr. James Bridges. The method and system of noise suppression via deflection of the bypass and/or core streams is proprietary to the University of California. U.S. Patent Pending.

\section{References}

${ }^{1}$ Papamoschou, D., "New Method for Jet Noise Suppression in Turbofan Engines,” AIAA Journal, Vol. 42, No.11, 2004, pp. 2245-2253.

${ }^{2}$ Papamoschou, D. and Nishi, K.A., "Jet Noise Suppression with Fan Flow Deflectors in Realistic-Shaped Nozzle," AIAA Paper 2005-0993, Jan. 2005.

${ }^{3}$ Zaman, K.B.M.Q., and Papamoschou, D. "Effect of a Wedge on Coannular Jet Noise”, AIAA Paper 2006-0007, Jan. 2006.

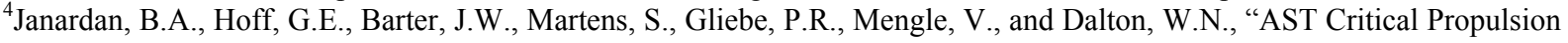
and Noise Reduction Technologies for Future Commercial Subsonic Engines Separate-Flow Exhaust System Noise Reduction Concept Evaluation," NASA CR 2000-210039.

${ }^{5}$ Papamoschou, D., "Parametric Study of Fan Flow Deflectors for Jet Noise Suppression," AIAA Paper 2005-2890, May 2005.

${ }^{6}$ Murayama, T., Papamoschou, D., and Liu, F. “Aerodynamics of Fan Flow Deflectors for Jet Noise Suppression,” AIAA Paper 2005-0994, Jan. 2005.

${ }^{7}$ Doty, M.J. and McLaughlin, D.K., "Acoustic and Mean Flow Measurements of High-Speed, Helium-Air Jets," International Journal of Aeroacoustics, Vol. 2, No. 3 \& 4, 2003, pp.293-333.

${ }^{8}$ Papamoschou, D. "Acoustic Simulation of Hot Coaxial Jets using Cold Helium-Air Mixture Jets," AIAA Paper 2005-0208, Jan. 2005. To appear in the AIAA Journal of Propulsion and Power. 
Table 1 Classic Nozzle Exit Conditions

\begin{tabular}{lcc}
\hline Quantity & Primary & Secondary \\
\hline Nozzle diameter $(\mathrm{mm})$ & 14.3 & 23.6 \\
Plug diameter $(\mathrm{mm})$ & 10.0 & - \\
Lip thickness $(\mathrm{mm})$ & 0.74 & - \\
Protrusion $(\mathrm{mm})$ & 9.5 & - \\
\hline Velocity $^{\mathrm{a}}(\mathrm{m} / \mathrm{s})$ & 460 & 335 \\
Mach number $^{\mathrm{a}}$ & 0.86 & 0.95 \\
Bypass ratio $^{\mathrm{a}}$ & - & 4.93 \\
\hline Velocity $^{\mathrm{b}}(\mathrm{m} / \mathrm{s})$ & 310 & 220 \\
Mach number & 1.0 & 0.66 \\
Bypass ratio & - & 1.92 \\
\hline \hline & & \\
& & \\
a & & \\
b mean velocity measurements &
\end{tabular}

Table 2 UCI 3BB Nozzle Exit Conditions

\begin{tabular}{lcc}
\hline Quantity & Primary & Secondary \\
\hline Nozzle diameter $(\mathrm{mm})$ & 17.0 & 31.0 \\
Plug diameter $(\mathrm{mm})$ & 11.5 & - \\
Lip thickness $(\mathrm{mm})$ & 2.2 & 3.1 \\
Protrusion $(\mathrm{mm})$ & 16.2 & - \\
\hline Velocity $^{\mathrm{a}}(\mathrm{m} / \mathrm{s})$ & 460 & 335 \\
Mach number $^{\mathrm{a}}$ & 0.86 & 0.95 \\
Bypass ratio $^{\mathrm{a}}$ & - & 4.8 \\
\hline Velocity $^{\mathrm{b}}(\mathrm{m} / \mathrm{s})$ & 310 & 220 \\
Mach number $^{\mathrm{b}}$ & 1.0 & 0.66 \\
Bypass ratio $^{\mathrm{b}}$ & - & 1.87 \\
\hline \hline
\end{tabular}

Table 3 Classic nozzle deflector configurations with turning effort $\varepsilon$ and reduction in peak OASPL (dB)

\begin{tabular}{llcc}
\hline Case & Configuration & $\varepsilon$ & $\Delta$ OASPL \\
\hline $\mathrm{W}_{\mathrm{i}}$ & Internal wedge with $\alpha=17^{\circ}, l=5 \mathrm{~mm}, x_{\text {apex }}=-4.8 \mathrm{~mm}$. & - & 1.4 \\
$\mathrm{~W}_{\mathrm{e}}$ (equal $\varepsilon$ ) & External wedge with $\alpha=18^{\circ}, l=10 \mathrm{~mm}, x_{\text {apex }}=0 \mathrm{~mm}$. & - & 2.8 \\
$2 \mathrm{~V}($ equal $\varepsilon)$ & One pair of vanes at $\phi=90^{\circ}, c=2 \mathrm{~mm}, \alpha=10^{\circ}, x_{t e}=0 \mathrm{~mm}$. & 0.03 & 1.5 \\
$2 \mathrm{~V}$ (equal chord) & One pair of vanes at $\phi=90^{\circ}, c=4 \mathrm{~mm}, \alpha=10^{\circ}, x_{t e}=0 \mathrm{~mm}$. & 0.06 & 2.4 \\
$4 \mathrm{~V}$ (equal $\varepsilon$ ) & Two pairs of vanes at $\phi=70^{\circ}$ and $\phi=110^{\circ}, c=2 \mathrm{~mm}, \alpha=10^{\circ}, x_{t e}=0 \mathrm{~mm}$. & 0.07 & 3.5 \\
$4 \mathrm{~V}$ (equal chord) & Two pairs of vanes at $\phi=70^{\circ}$ and $\phi=110^{\circ}, c=4 \mathrm{~mm}, \alpha=10^{\circ}, x_{t e}=0 \mathrm{~mm}$. & 0.13 & 3.8 \\
\hline \hline
\end{tabular}

Table 4 UCI 3BB nozzle deflector configurations with turning effort $\varepsilon$ and reduction in peak OASPL (dB)

\begin{tabular}{llcc}
\hline Case & Configuration & $\varepsilon$ & $\Delta$ OASPL \\
\hline $\mathrm{W}_{\mathrm{i}}$ & Internal wedge with $\alpha=17^{\circ}, l=5 \mathrm{~mm}$. & - & 5.3 \\
$\mathrm{~W}_{\mathrm{e}}$ & External wedge with $\alpha=18^{\circ}, l=10 \mathrm{~mm}$. & - & 4.2 \\
$2 \mathrm{~V}$ & One pair of vanes at $\phi=90^{\circ}, c=4 \mathrm{~mm}, \alpha=10^{\circ}, x_{t e}=0 \mathrm{~mm}$. & 0.03 & 3.8 \\
$4 \mathrm{~V}$ & Two pairs of vanes at $\phi=70^{\circ}$ and $\phi=110^{\circ}, c=4 \mathrm{~mm}, \alpha=10^{\circ}, x_{t e}=0 \mathrm{~mm}$. & 0.06 & 5.0 \\
\hline \hline
\end{tabular}

$\alpha=$ angle of attack for vane, half-angle for wedge

$c=$ chord length of vane airfoil

$l=$ length of side of wedge

$\phi=$ azimuth angle measured from the downward vertical direction

$x_{t e}=$ axial location of trailing edge relative to exit of fan nozzle

$x_{\text {apex }}=$ axial location of wedge apex relative to exit of fan nozzle 


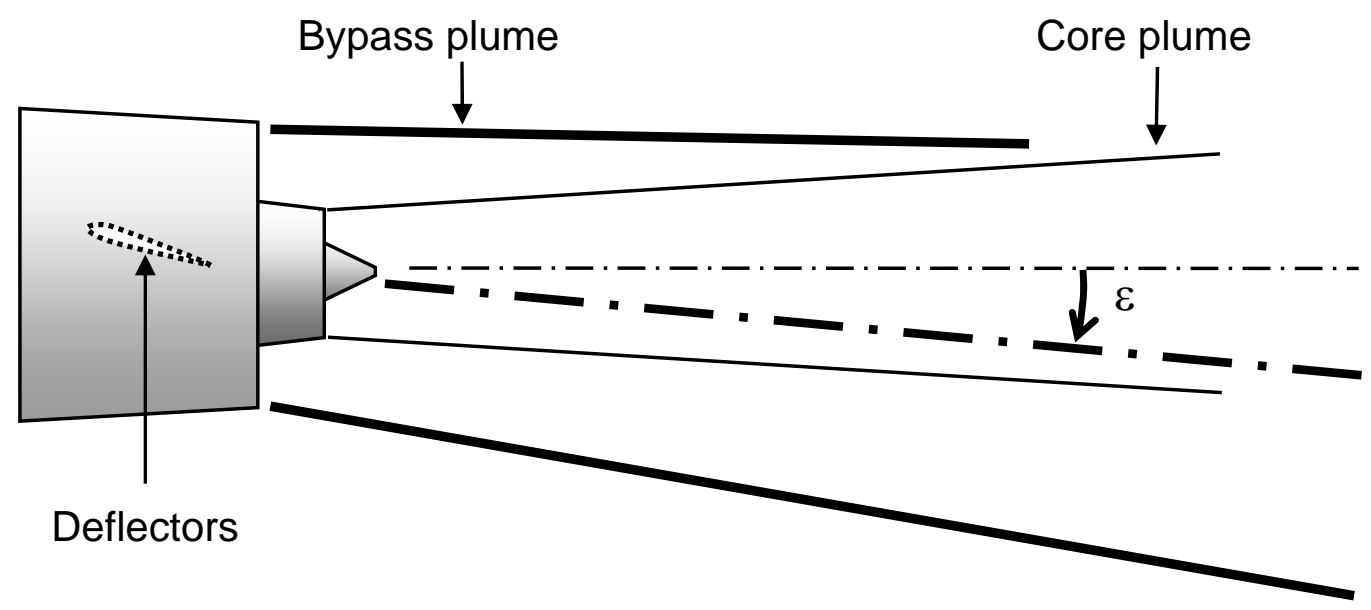

Figure 1. General Concept of fan flow deflection (FFD).

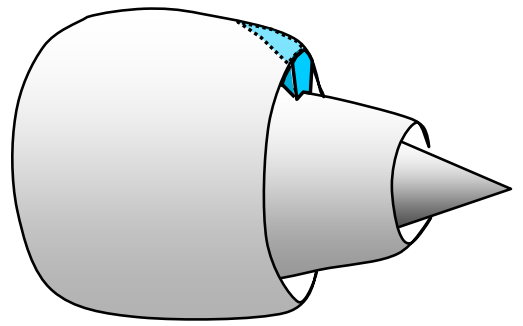

a) Internal Wedge $-W_{i}$

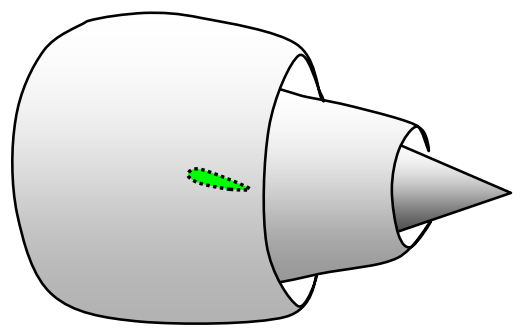

c) Single Vane Pair - 2V

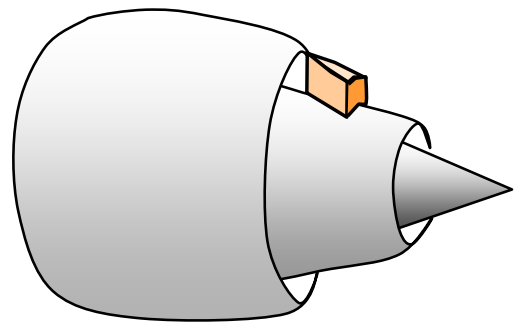

b) External Wedge - $W_{e}$

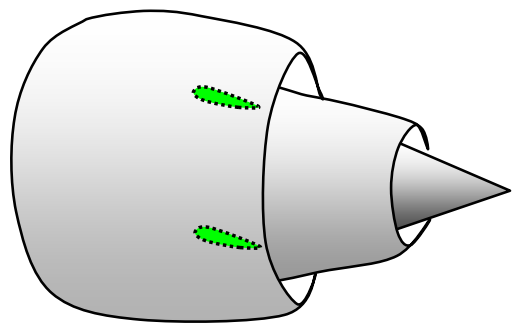

d) Two Vane Pairs - 4V

Figure 2. Depiction of deflector configurations tested. 


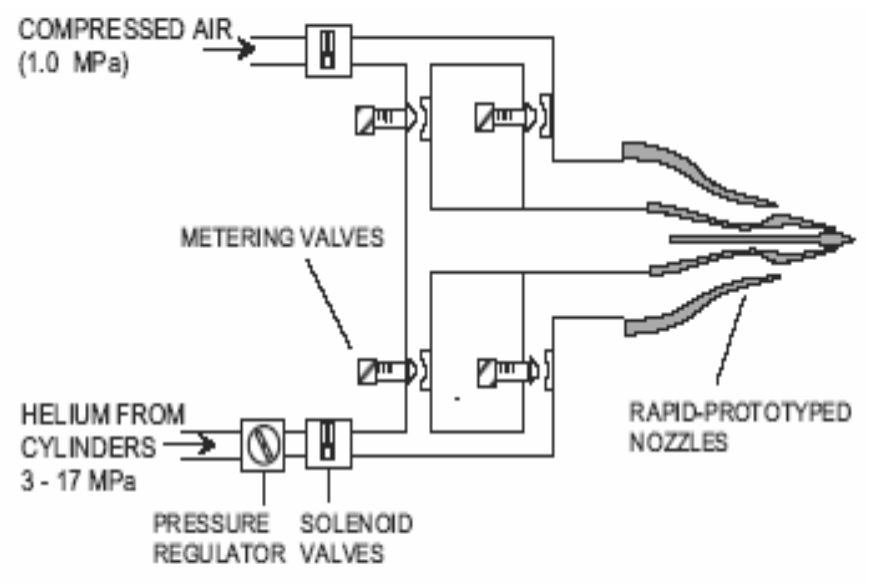

a) Dual-stream apparatus

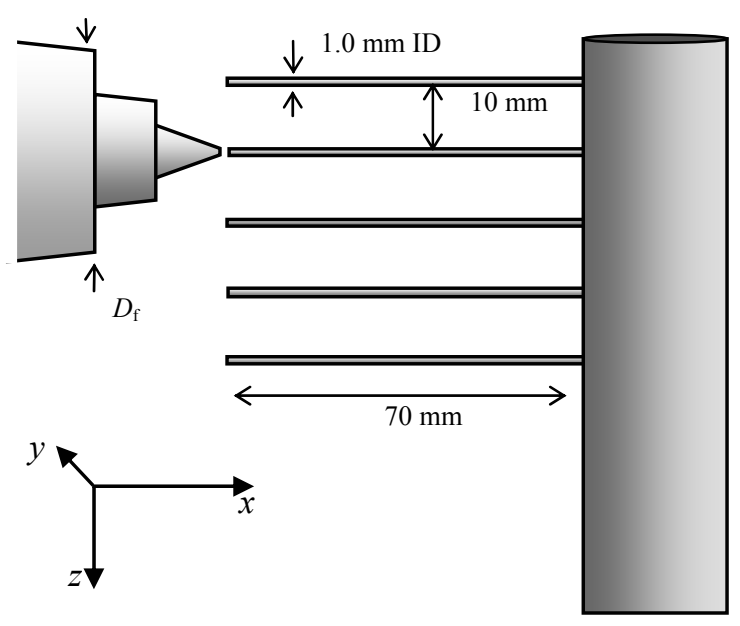

b) Pitot tube rake

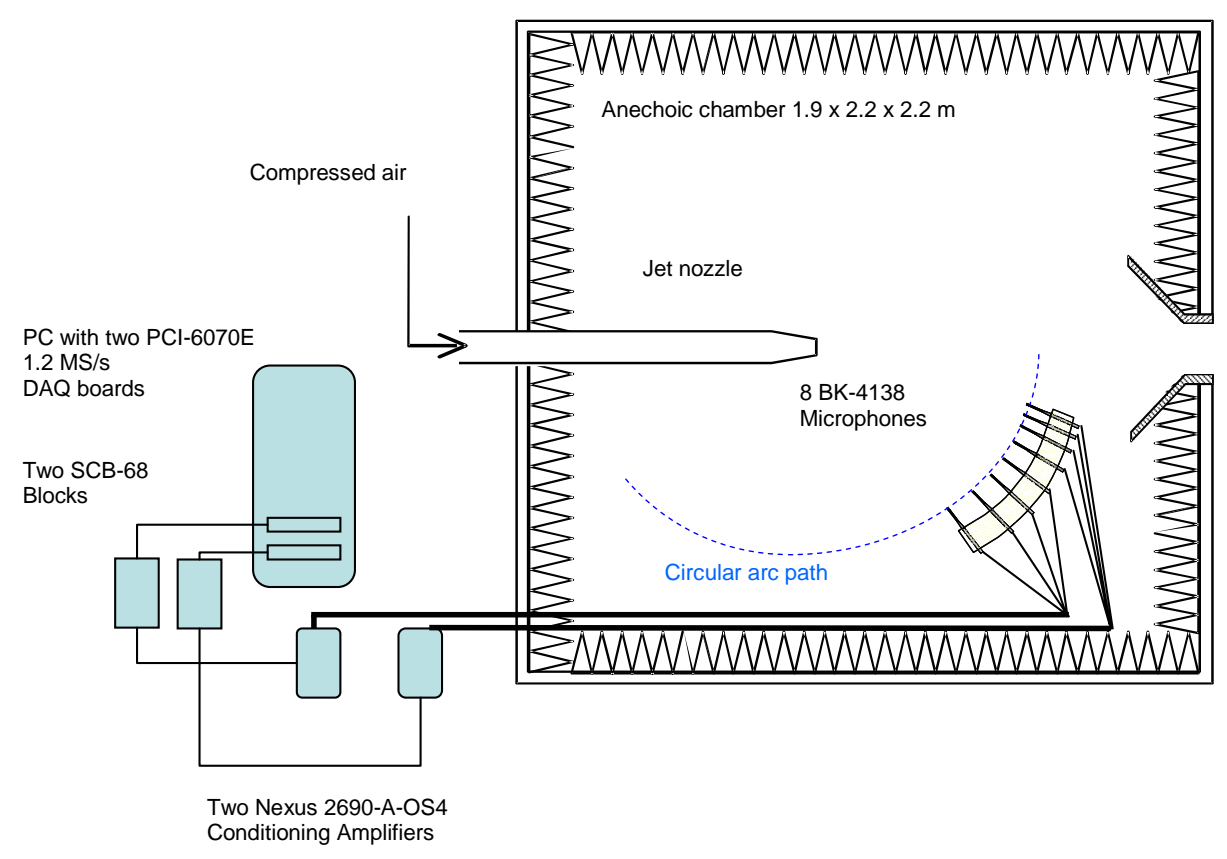

c) Anechoic chamber

Figure 3. UCI Jet Aeroacoustics Facility. 

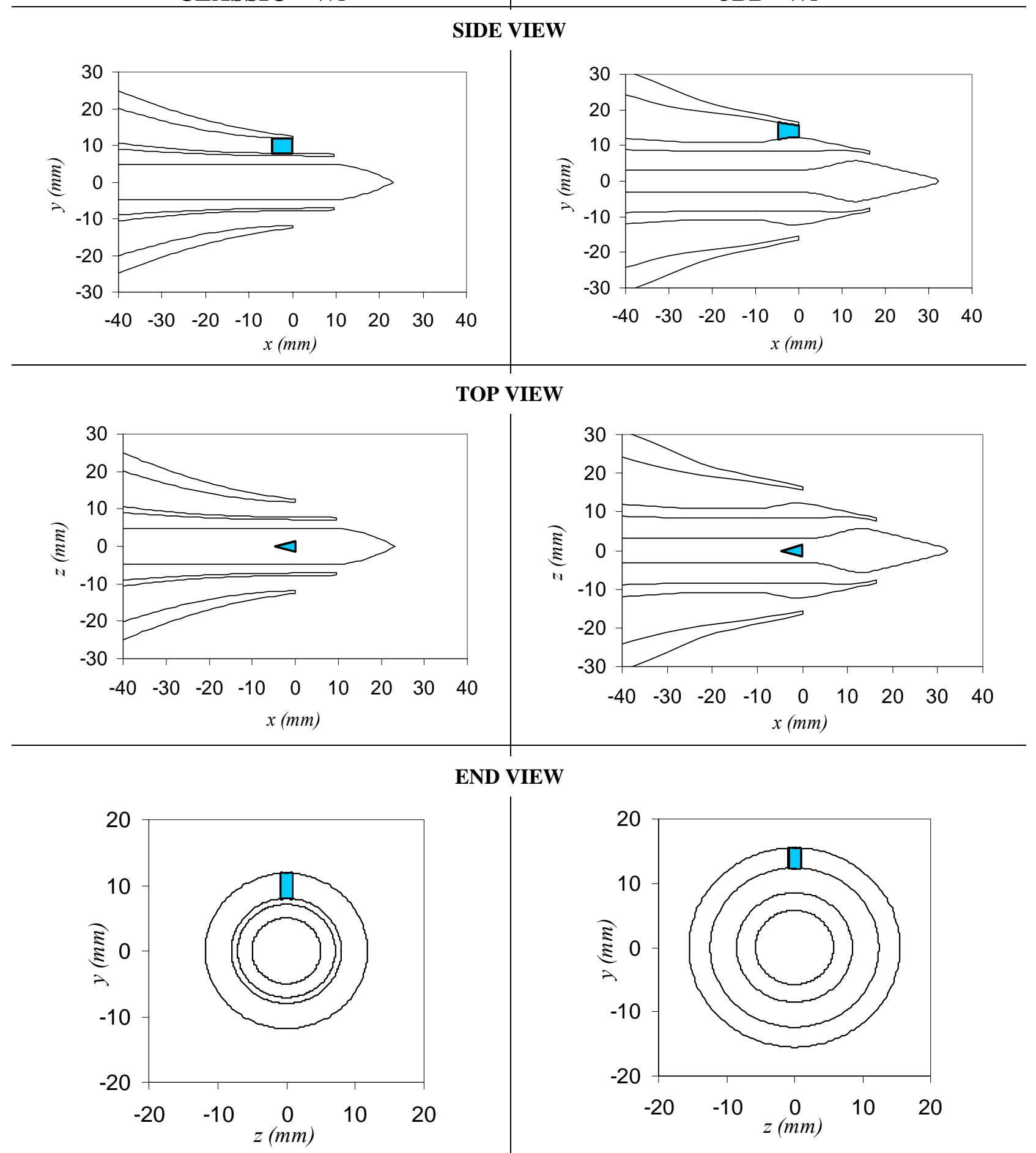

END VIEW

Figure 4. Coordinates of the CLASSIC (left) and 3BB (right) nozzles with internal wedge (Wi). The wedge side length is $5 \mathrm{~mm}$, and the half angle is $17^{\circ}$. The wedge base is placed at $x=0$, on the fan exit plane. 


\section{SIDE VIEW}
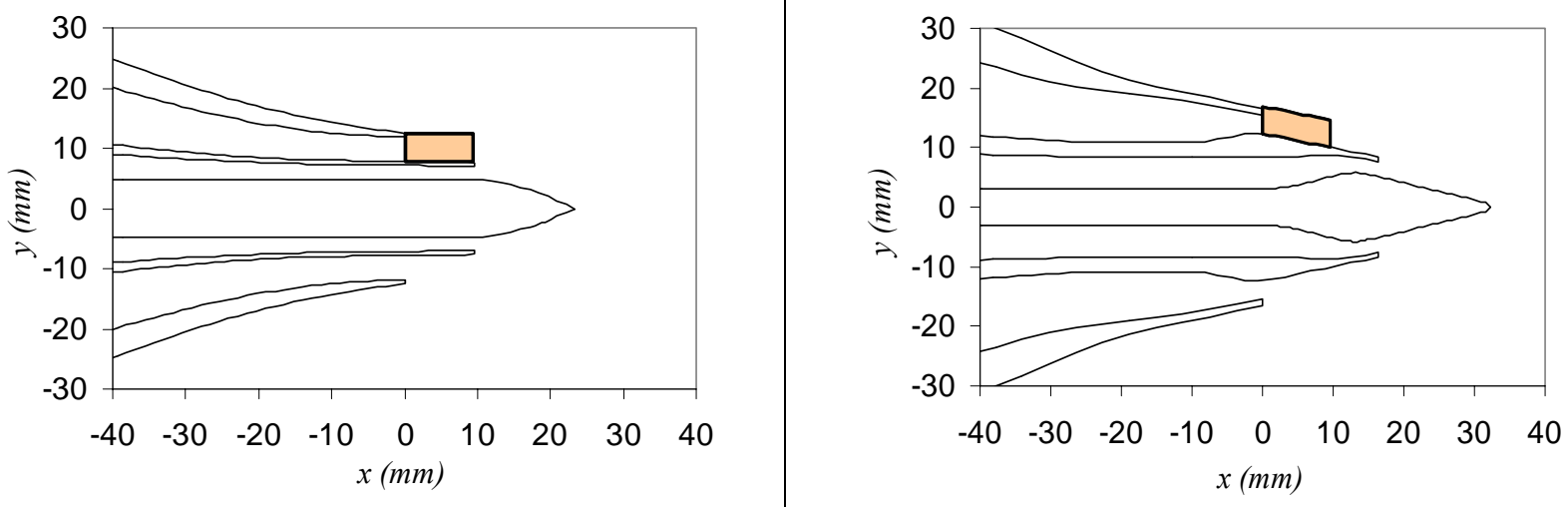

TOP VIEW
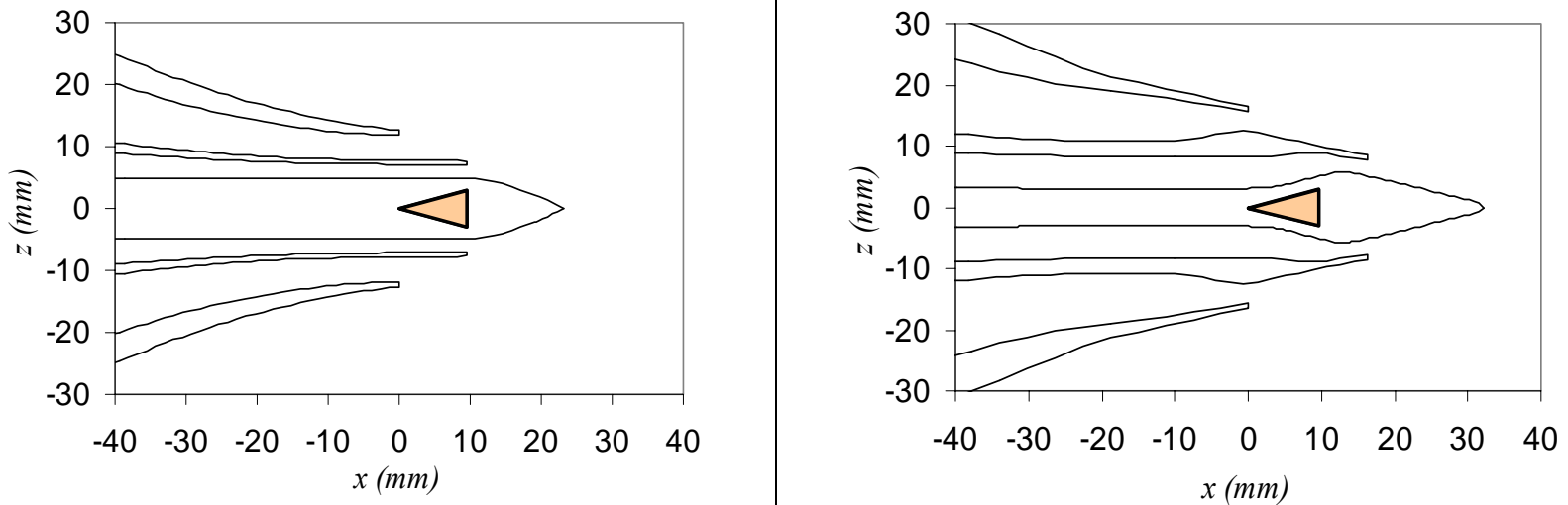

\section{END VIEW}
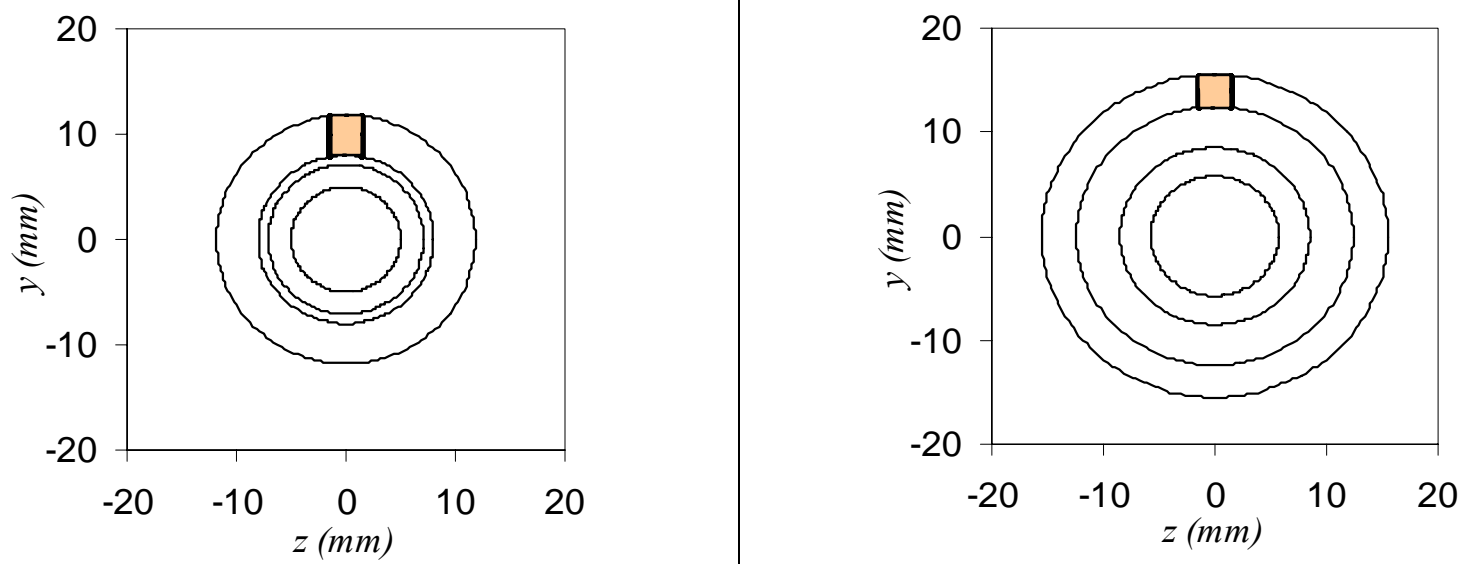

Figure 5. Coordinates of the CLASSIC (left) and 3BB (right) nozzles with external wedge (We). The wedge side length is $10 \mathrm{~mm}$, and the half angle is $18^{\circ}$. The wedge apex is placed at $x=0 \mathrm{~mm}$ (fan exit plane). 


\section{TOP VIEW}
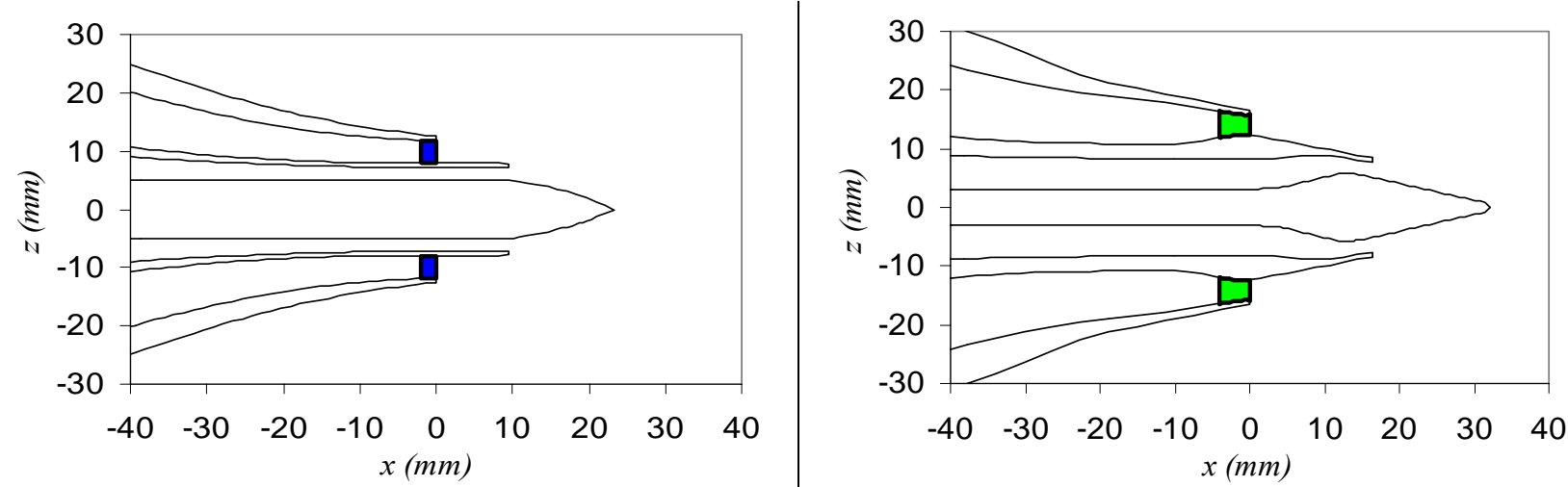

a)

\section{TOP VIEW}
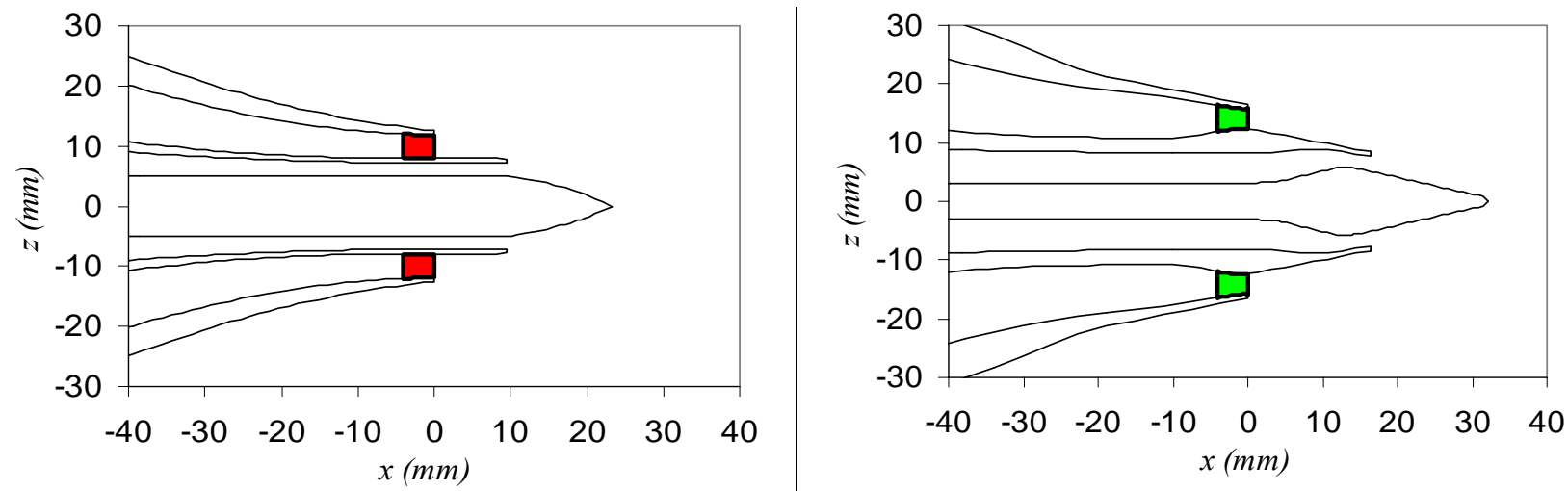

b)

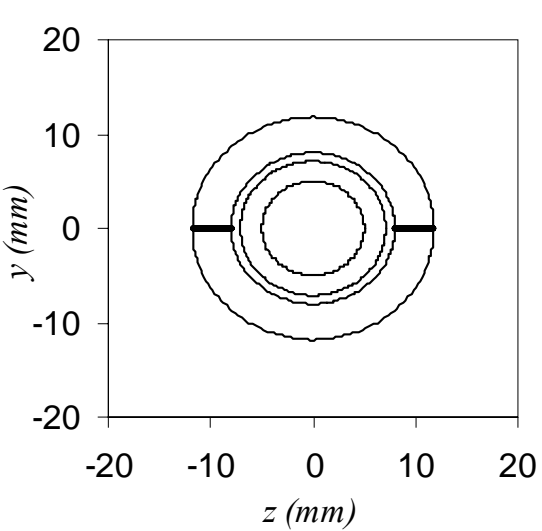

\section{END VIEW}

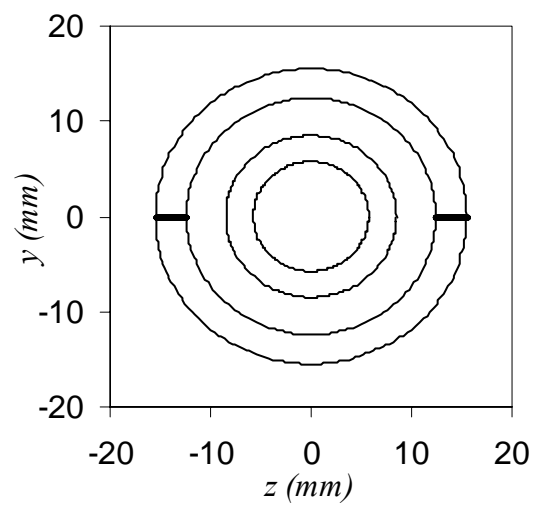

c)

Figure 6. Coordinates for the CLASSIC (left) and 3BB (right) nozzles with one pair of vanes (2V). a) For the equal turning effort comparison, the vane chord length is $c=2 \mathrm{~mm}$ in the classic nozzle and $c=4 \mathrm{~mm}$ in the $3 B B$ nozzle. b) For the equal chord comparison, the vane chord length is $\mathrm{c}=\mathbf{4} \mathrm{mm}$ in both nozzles. c) End views. 


\section{TOP VIEW}
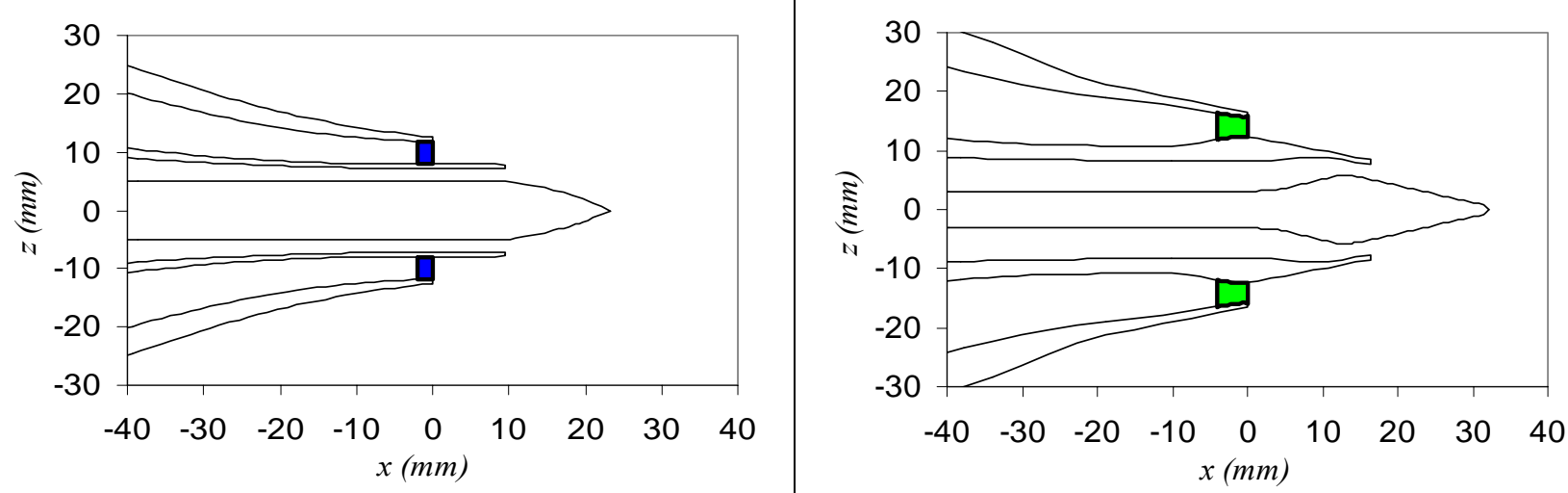

a)

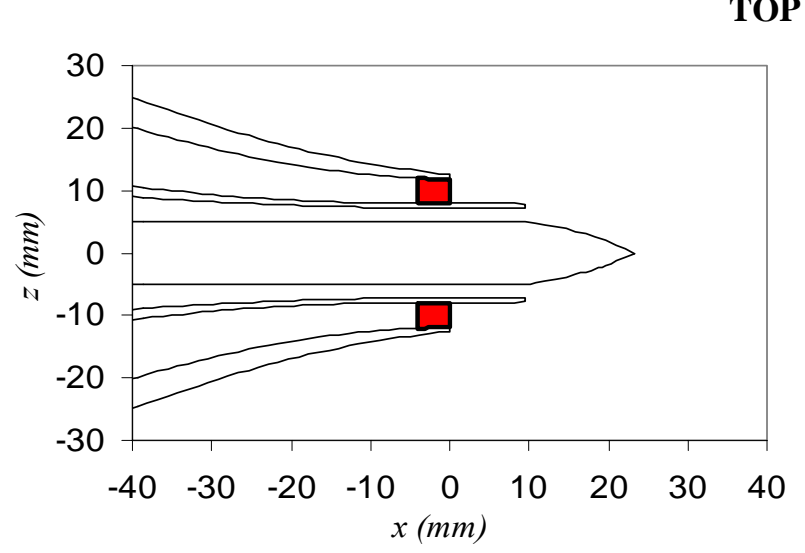

TOP VIEW

b)
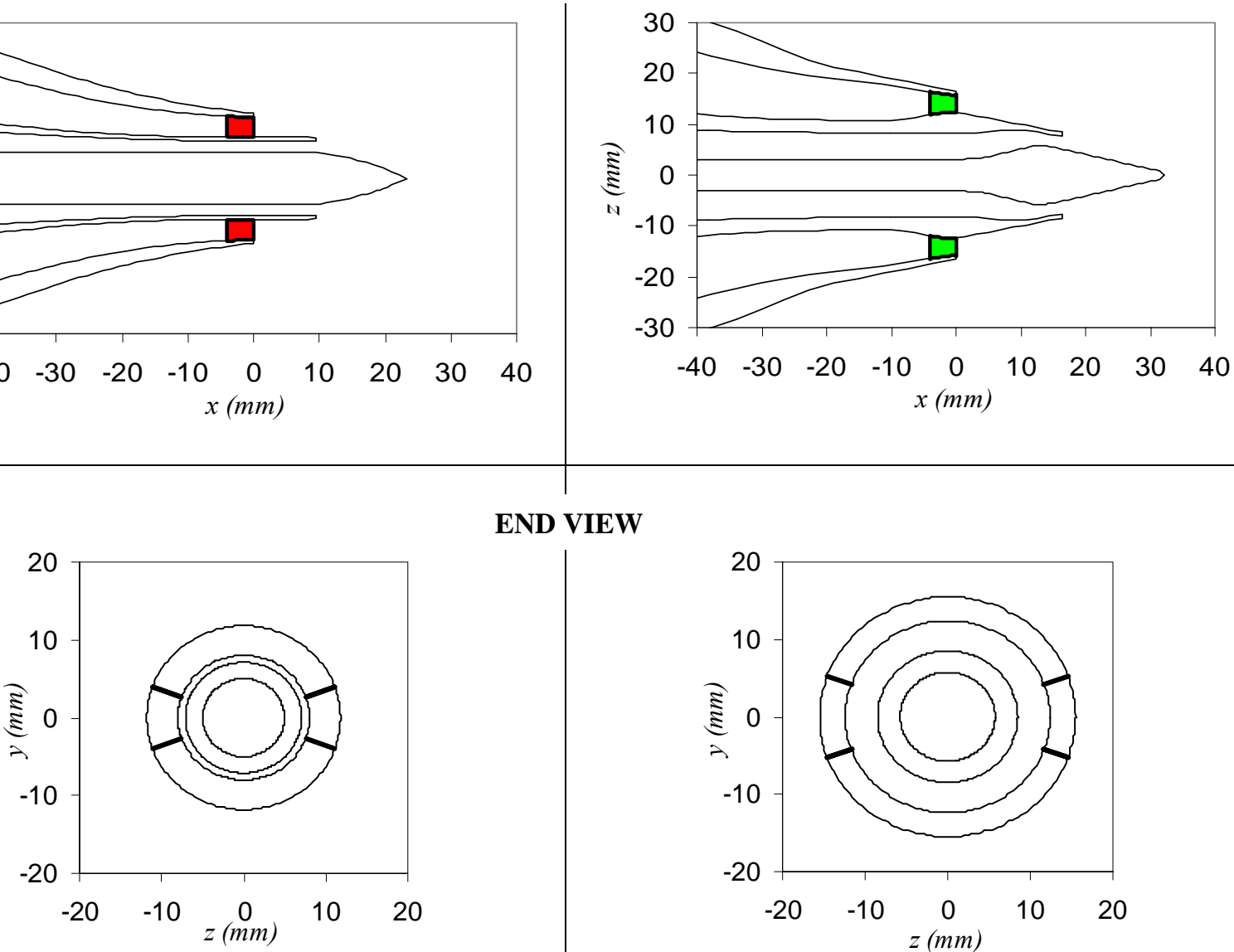

END VIEW

c)

Figure 7. Coordinates for the CLASSIC (left) and 3BB (right) nozzles with two pairs of vanes $(4 \mathrm{~V})$. a) For the equal turning effort comparison, $c=2 \mathrm{~mm}$ in the classic nozzle and $\mathrm{c}=4 \mathrm{~mm}$ in the $3 B \mathrm{BB}$ nozzle. $b$ ) For the equal chord comparison, $c=4 \mathrm{~mm}$ in both nozzles. $c$ ) End views. 


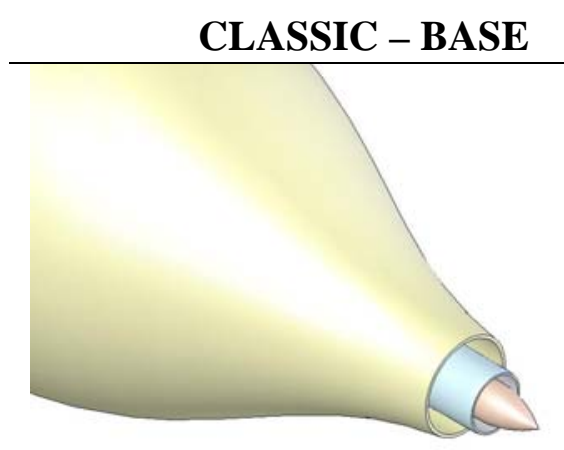

a)
3BB - BASE

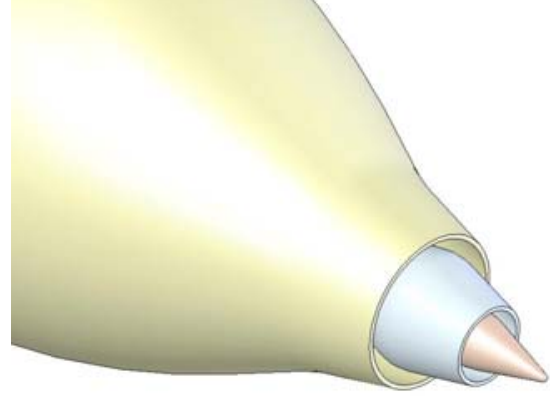

b)

Figure 8. Persepective views of a) CLASSIC and b) 3BB baseline nozzles.

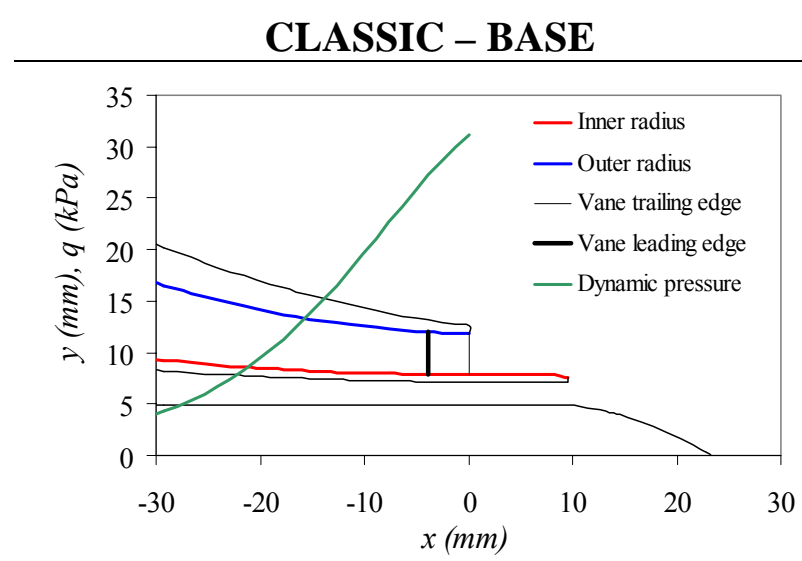

a)
3BB - BASE

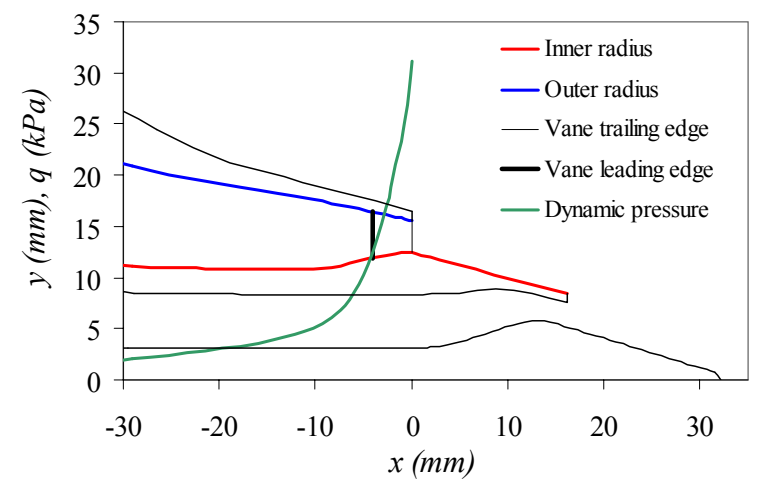

b)

Figure 9. Dynamic pressure distributions with vane deflector placement in (a) CLASSIC nozzle and (b) 3BB nozzle.

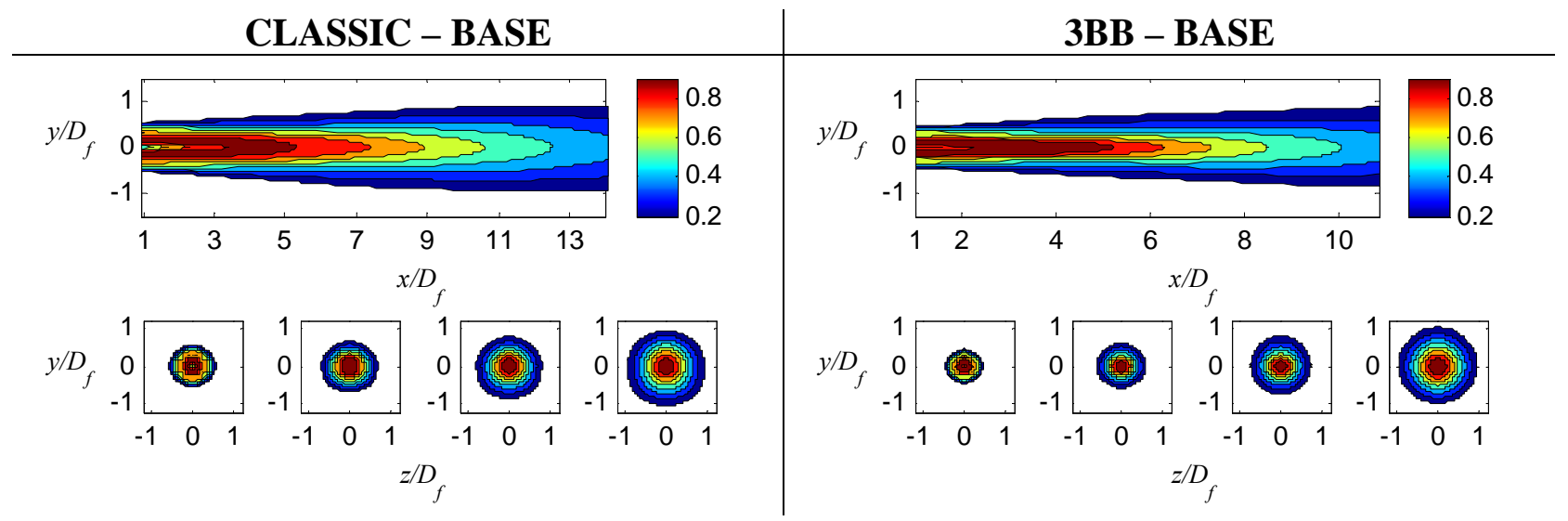

Figure 10. Flow field of jets issuing from baseline CLASSIC and 3BB nozzles. Isocontours of $u(x, y, 0) / U_{\mathrm{p}}$ and $\mathrm{u}\left(x_{0}, y, z\right) / u_{\max }(x)$ where $x_{0} / D_{\mathrm{f}}=1,3.5,6,8.5$ from left to right. 

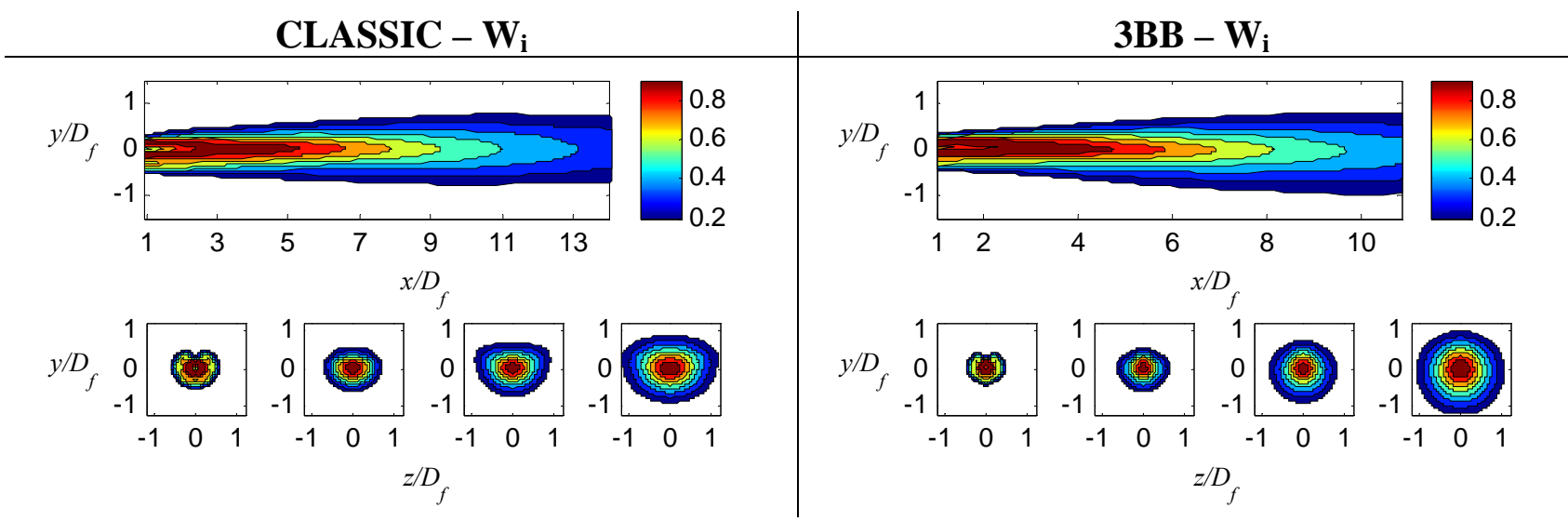

a) Isocontours of $u(x, y, 0) / U_{\mathrm{p}}$ and $u\left(x_{0}, y, z\right) / u_{\max }(x)$ where $x_{0} / D_{\mathrm{f}}=1,3.5,6,8.5$ from left to right.
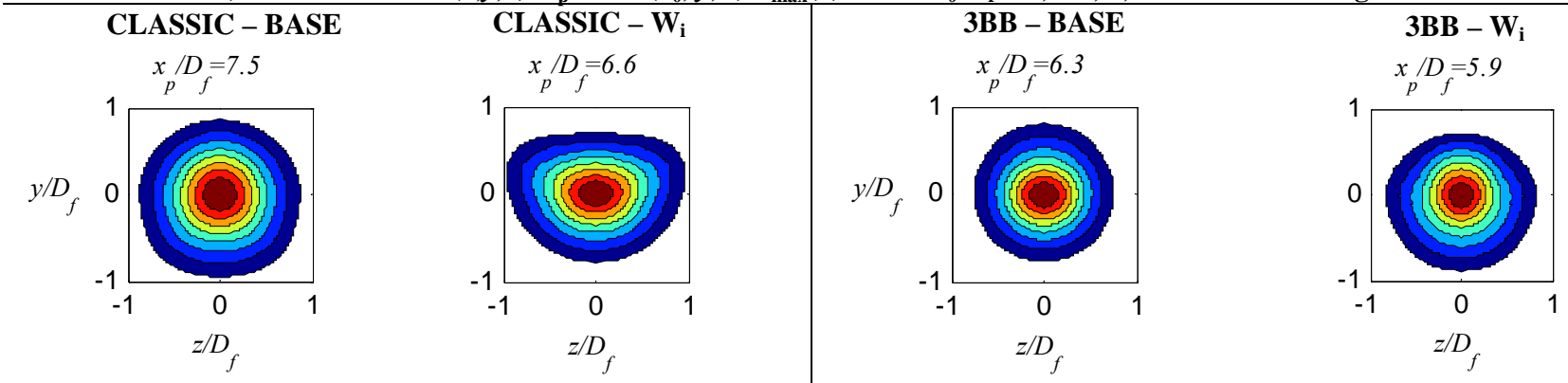

b) Isocontours of $\mathrm{u}\left(x_{\mathrm{p}}, y, z\right) / u_{\max }\left(x_{p}\right)$ where $x_{\mathrm{p}}$ denotes the point where $u_{\max }(x) / U_{\mathrm{p}}=0.8$.
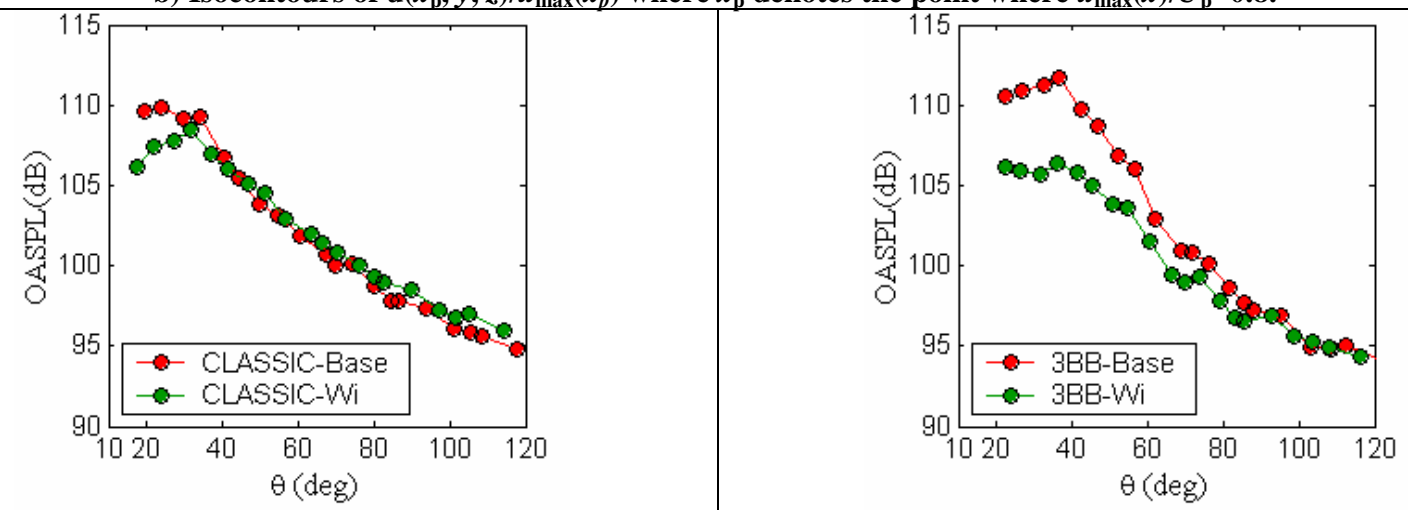

c) Directivity of overall sound pressure level.
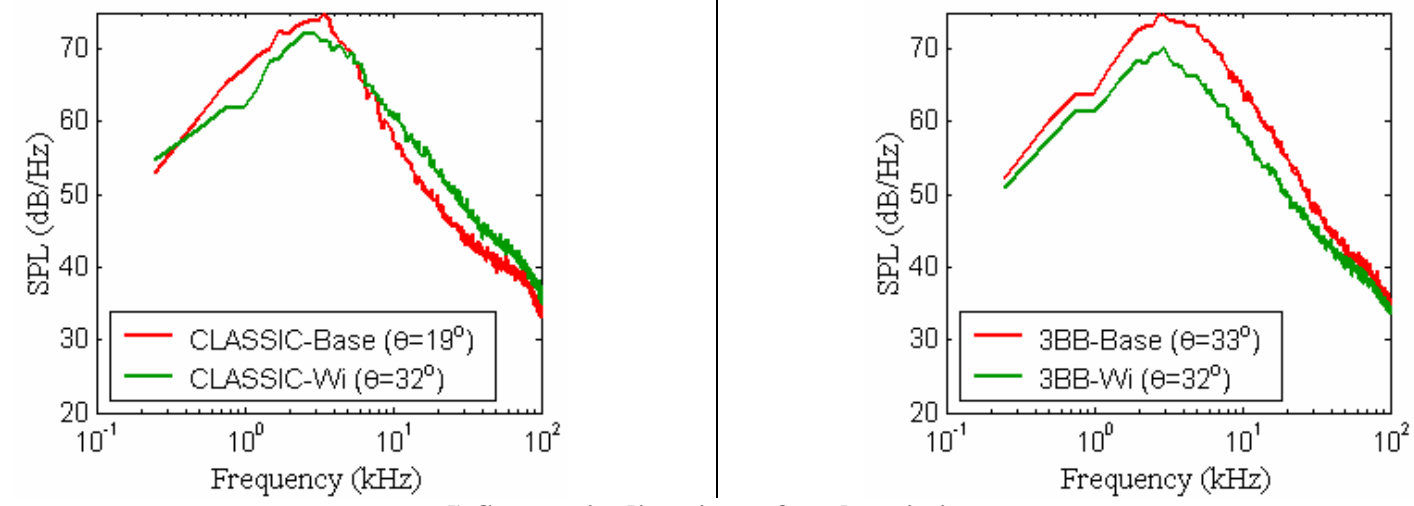

d) Spectra in directions of peak emission.

Figure 11. Flow field and acoustics of jets issuing from CLASSIC and 3BB nozzles with internal wedge $\left(\mathrm{W}_{\mathrm{i}}\right)$. 


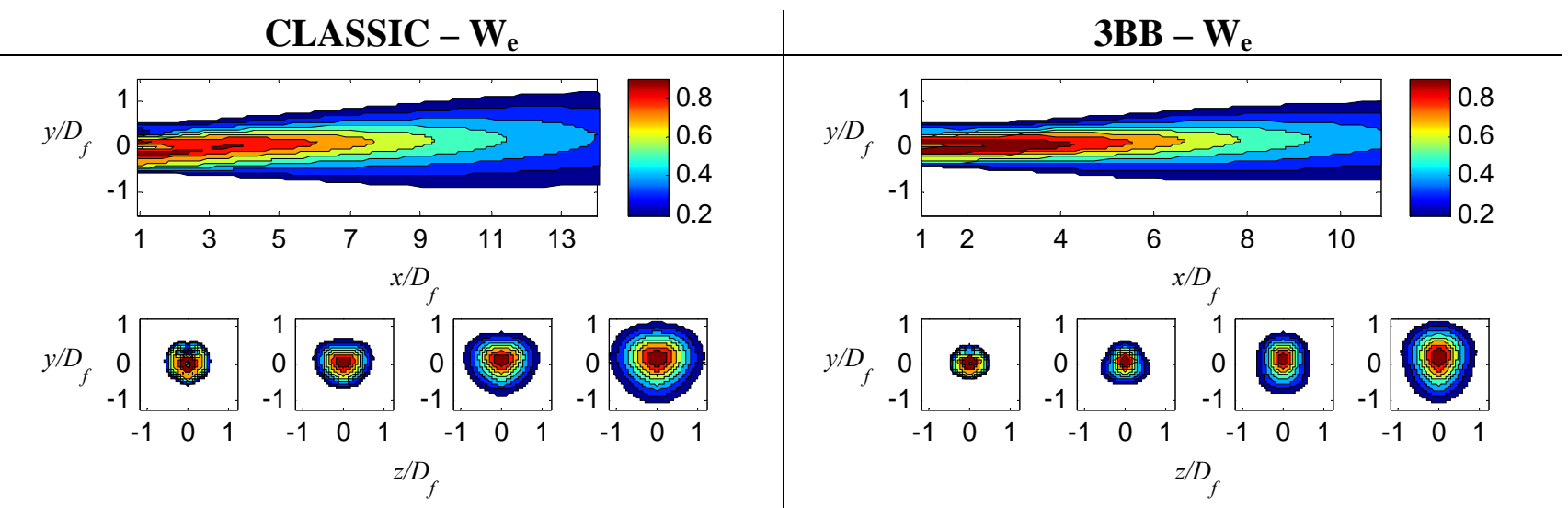

a) Isocontours of $u(x, y, 0) / U_{\mathrm{p}}$ and $\mathrm{u}\left(x_{0}, y, z\right) / u_{\max }(x)$ where $x_{0} / D_{\mathrm{f}}=1,3.5,6,8.5$ from left to right.
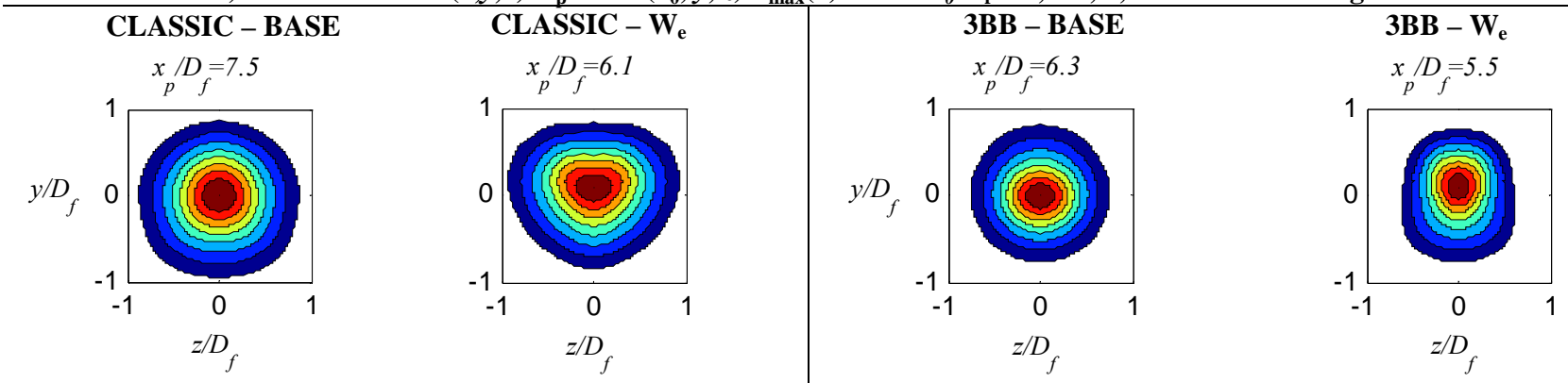

b) Isocontours of $\mathrm{u}\left(x_{\mathrm{p}}, y, z\right) / u_{\max }\left(x_{p}\right)$ where $x_{\mathrm{p}}$ denotes the point where $u_{\max }(x) / U_{\mathrm{p}}=\mathbf{0 . 8}$.
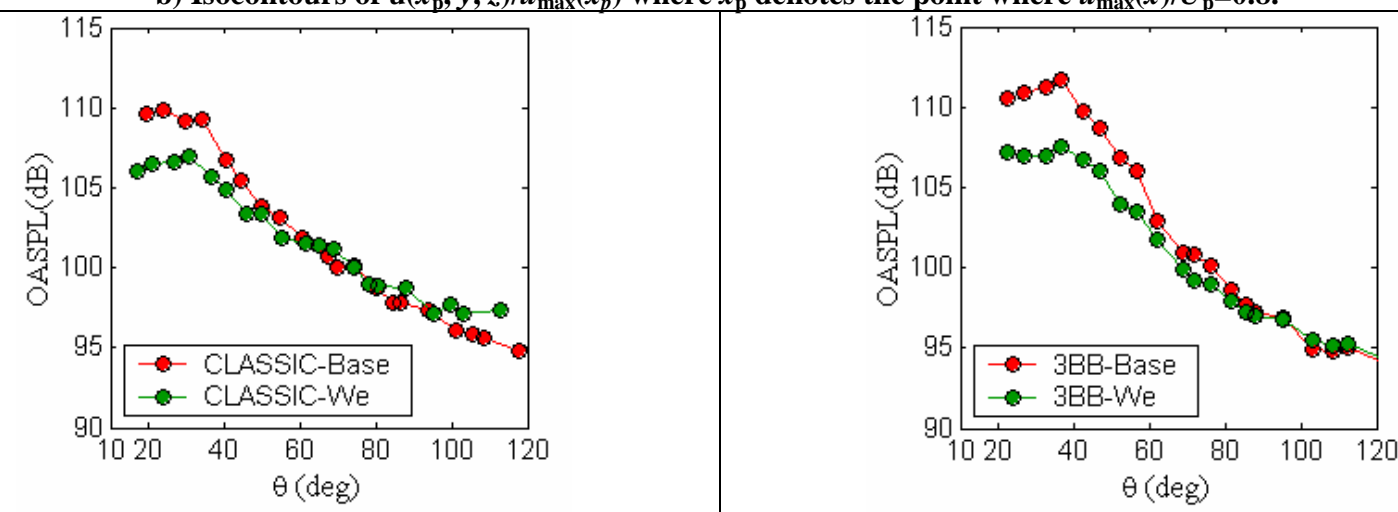

c) Directivity of overall sound pressure level.
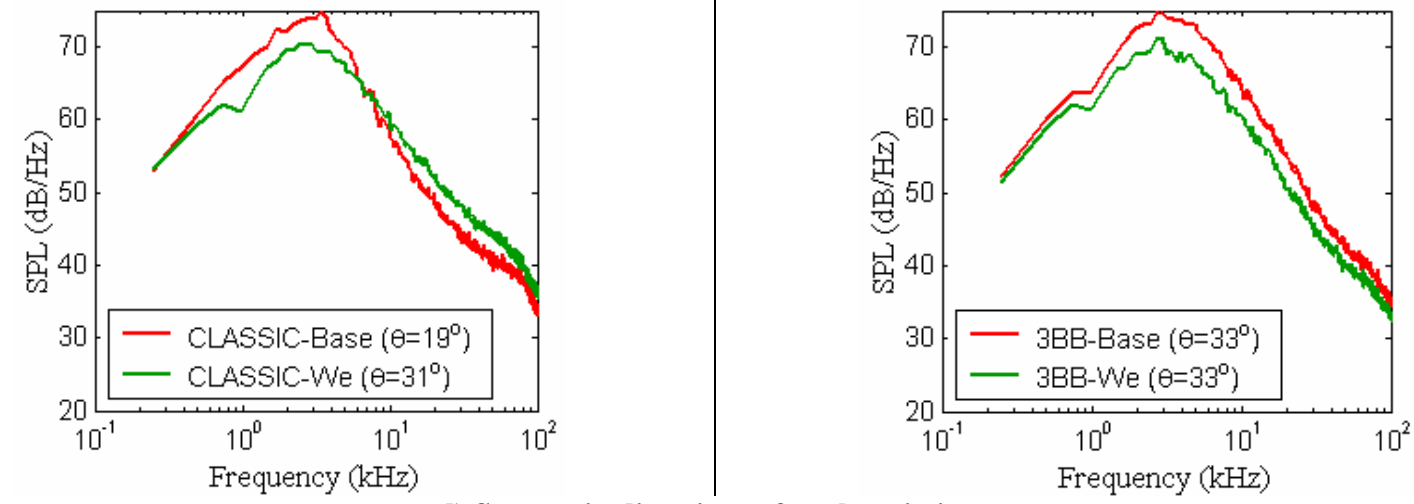

d) Spectra in directions of peak emission.

Figure 12. Flow field and acoustics of jets issuing from CLASSIC and 3BB nozzles with external wedge $\left(\mathrm{W}_{\mathrm{e}}\right)$. 

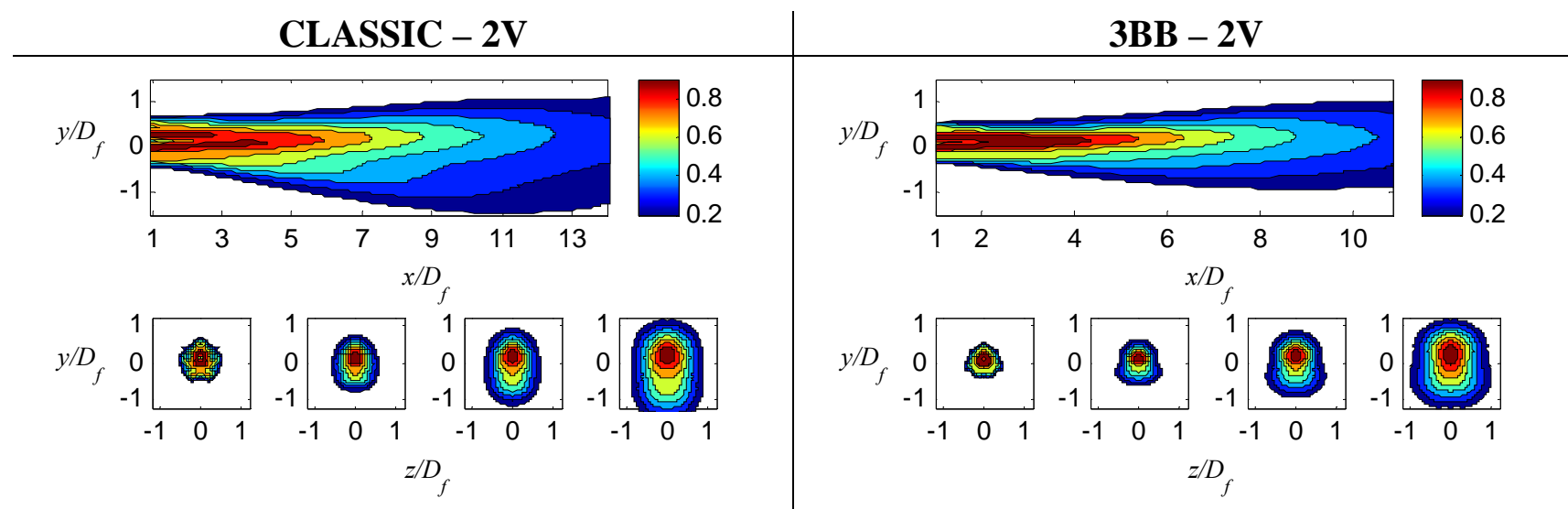

a) Isocontours of $u(x, y, 0) / U_{\mathrm{p}}$ and $u\left(x_{0}, y, z\right) / u_{\max }(x)$ where $x_{0} / D_{\mathrm{f}}=1,3.5,6,8.5$ from left to right.
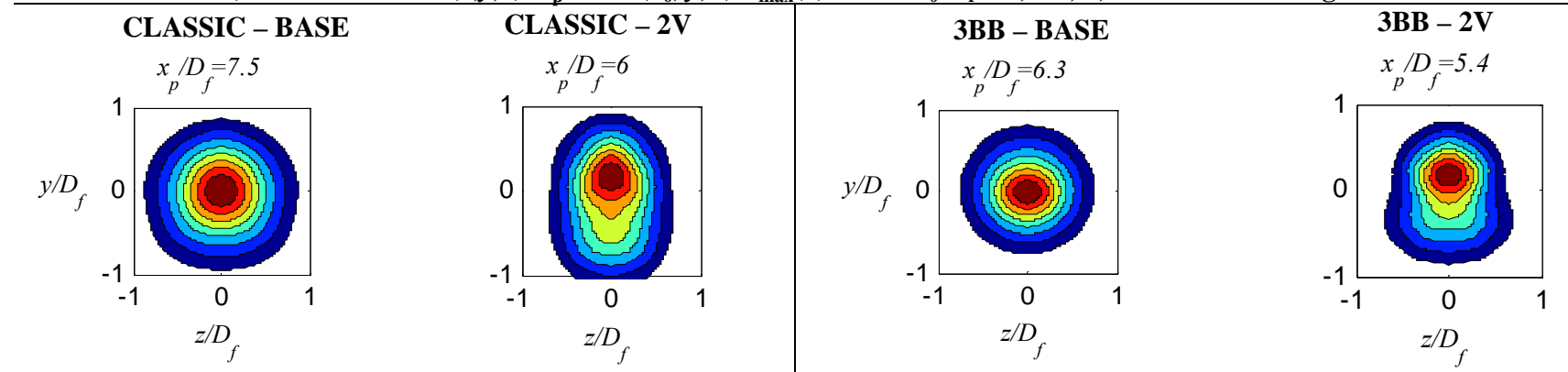

b) Isocontours of $u\left(x_{p}, y, z\right) / u_{\max }\left(x_{p}\right)$ where $x_{p}$ denotes the point where $u_{\max }(x) / U_{p}=0.8$.
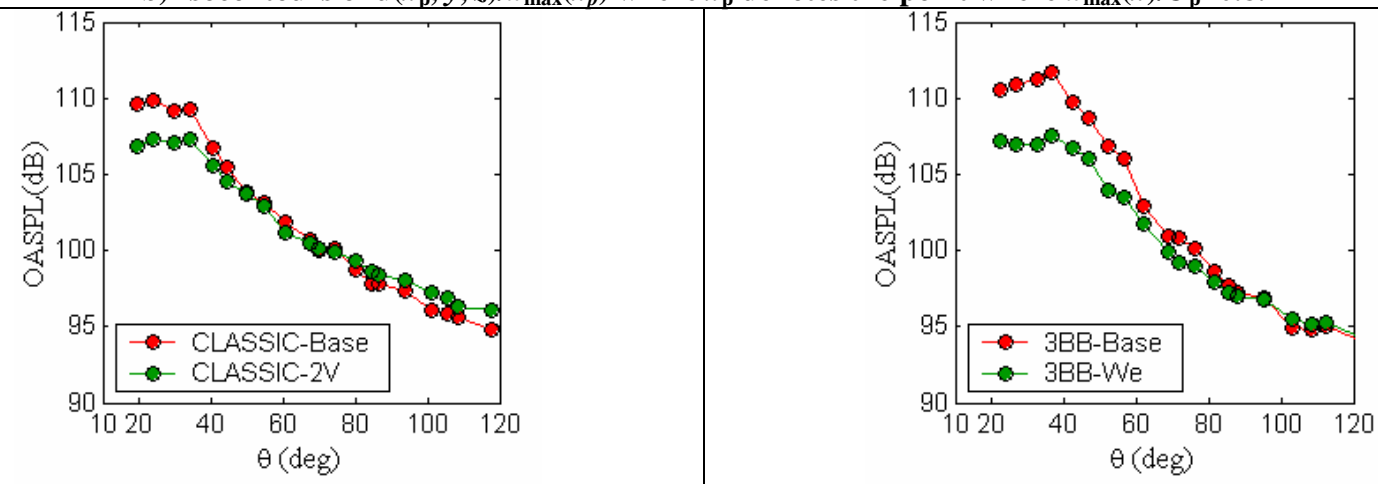

c) Directivity of overall sound pressure level.

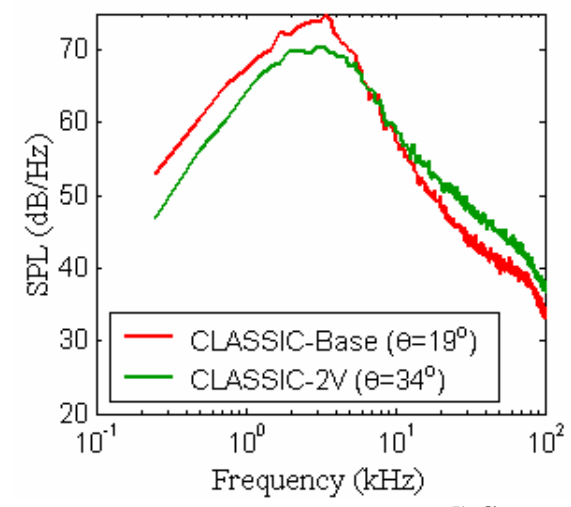

d) Spectra in directions of peak emission.

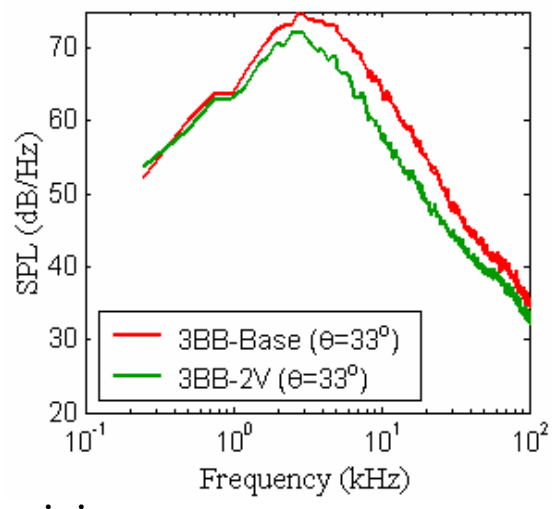

Figure 13. Flow field and acoustics of jets issuing from CLASSIC and 3BB nozzles with a single pair of vanes (2V). Comparison at equal turning effort. 

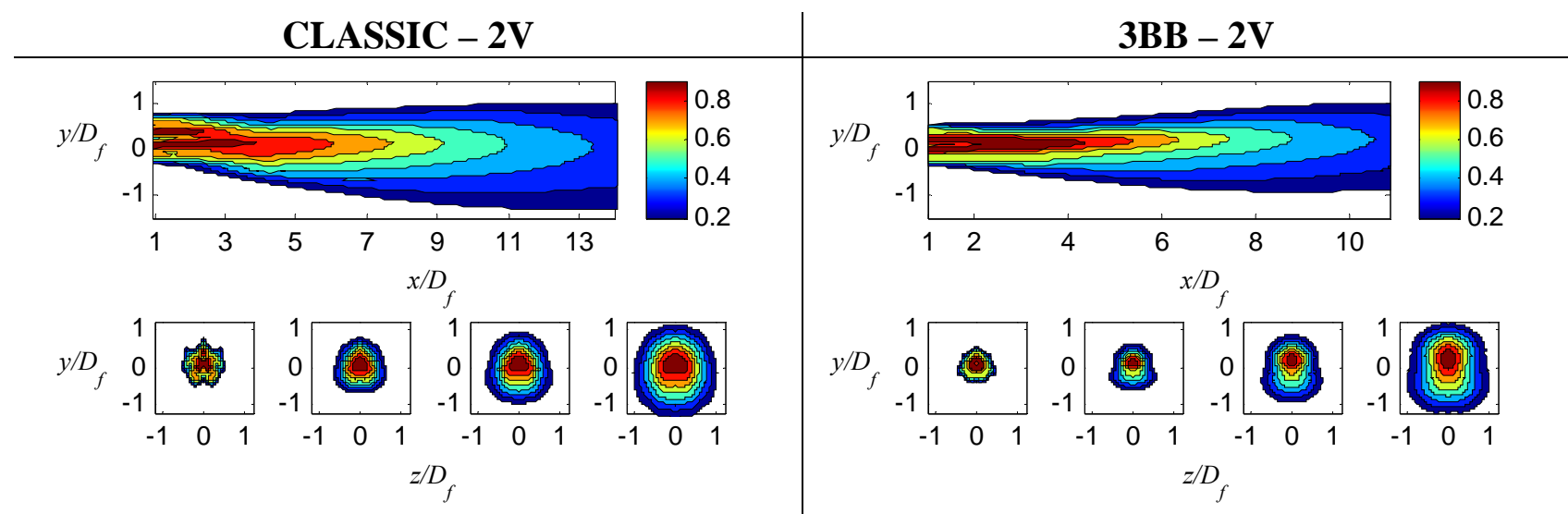

a) Isocontours of $u(x, y, 0) / U_{\mathrm{p}}$ and $u\left(x_{0}, y, z\right) / u_{\max }(x)$ where $x_{0} / D_{\mathrm{f}}=1,3.5,6,8.5$ from left to right.
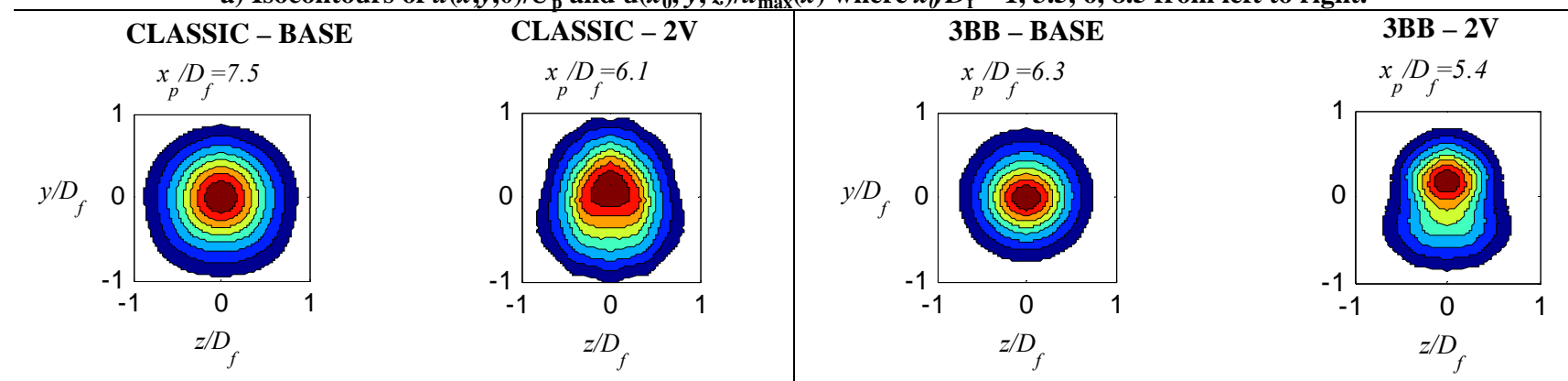

b) Isocontours of $u\left(x_{p}, y, z\right) / u_{\max }\left(x_{p}\right)$ where $x_{p}$ denotes the point where $u_{\max }(x) / U_{p}=0.8$.
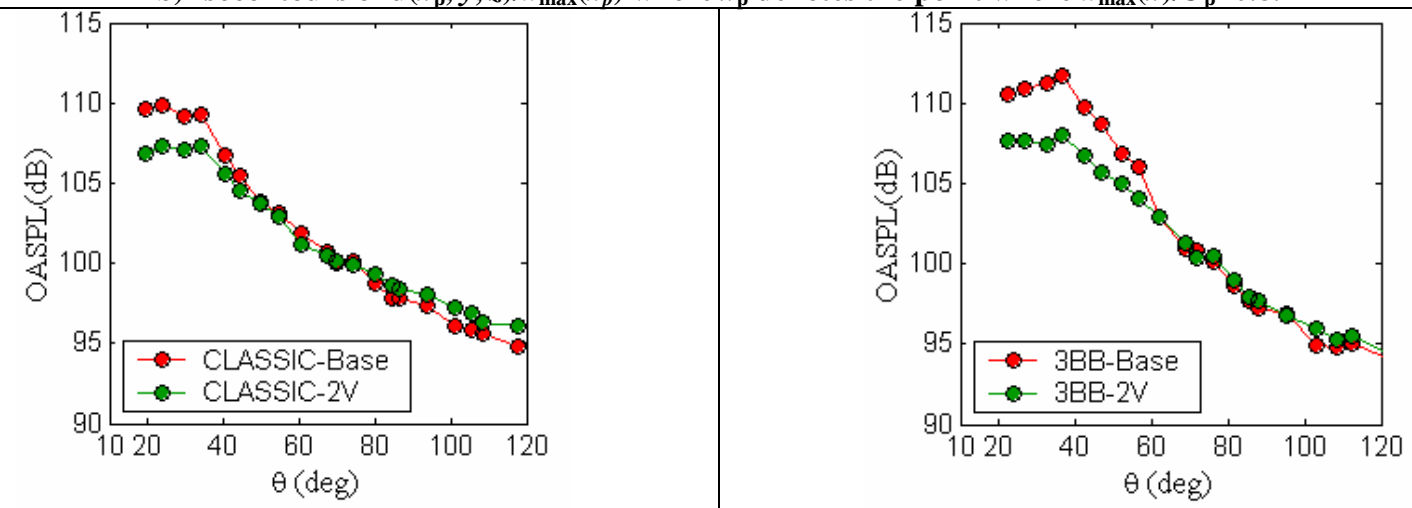

c) Directivity of overall sound pressure level.
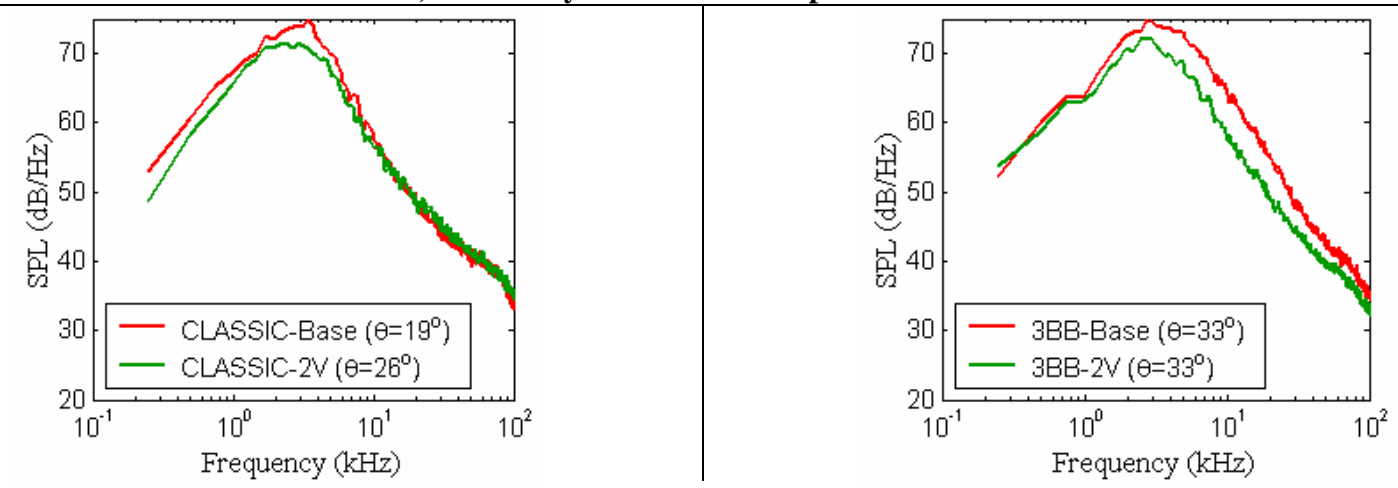

d) Spectra in directions of peak emission.

Figure 14. Flow field and acoustics of jets issuing from CLASSIC and 3BB nozzles with a single pair of vanes (2V). Comparison at equal chord length. 


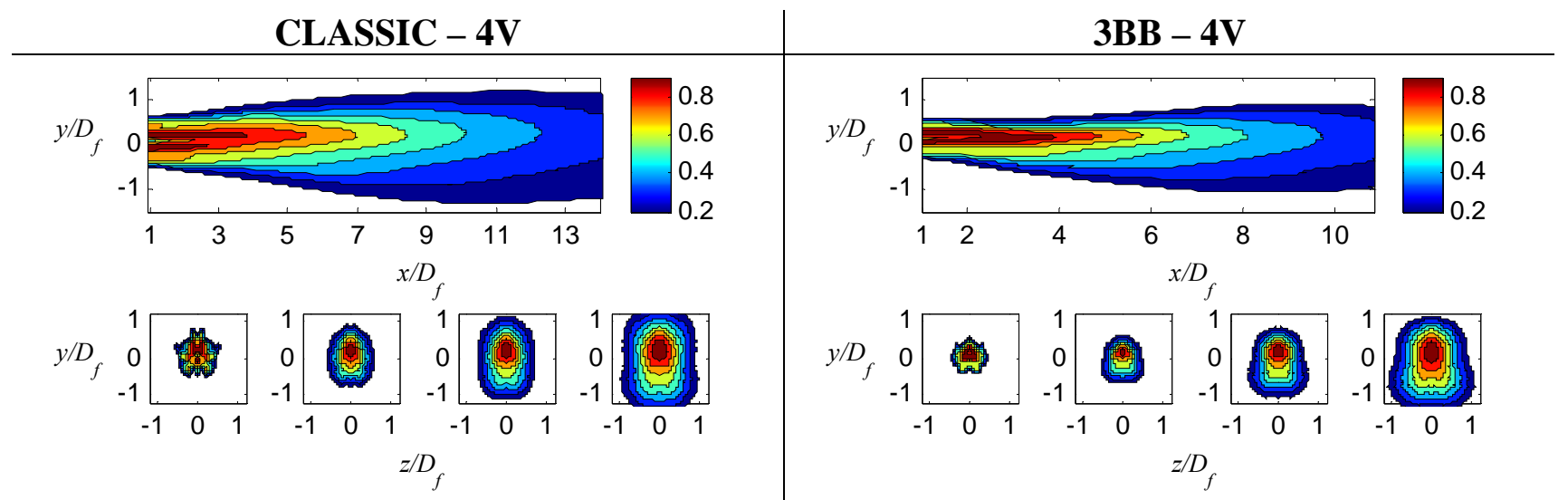

a) Isocontours of $u(x, y, 0) / U_{\mathrm{p}}$ and $u\left(x_{0}, y, z\right) / u_{\max }(x)$ where $x_{0} / D_{\mathrm{f}}=1,3.5,6,8.5$ from left to right.
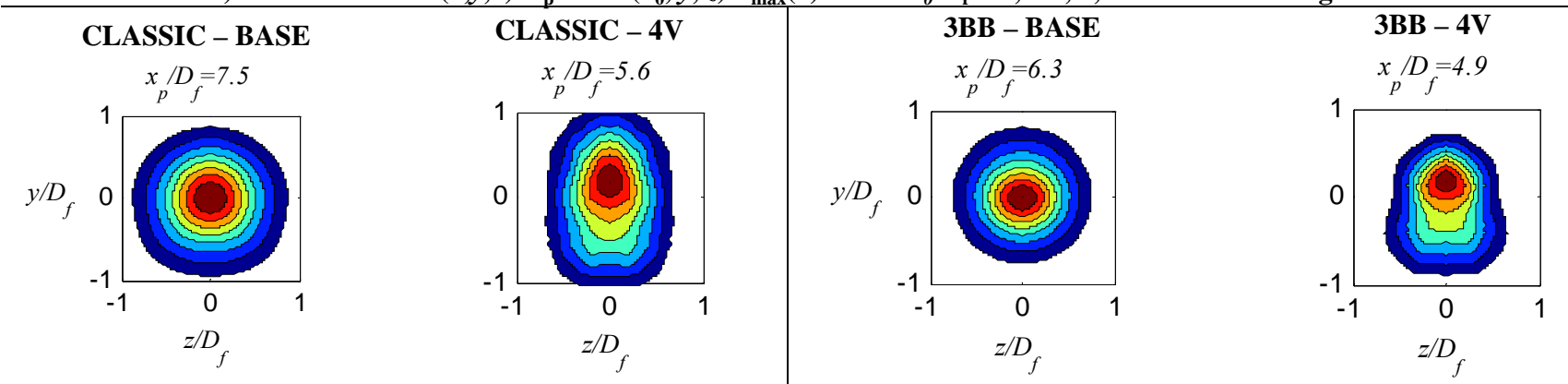

b) Isocontours of $\mathrm{u}\left(x_{\mathrm{p}}, y, z\right) / u_{\max }\left(x_{p}\right)$ where $x_{\mathrm{p}}$ denotes the point where $u_{\max }(x) / U_{\mathrm{p}}=0.8$.
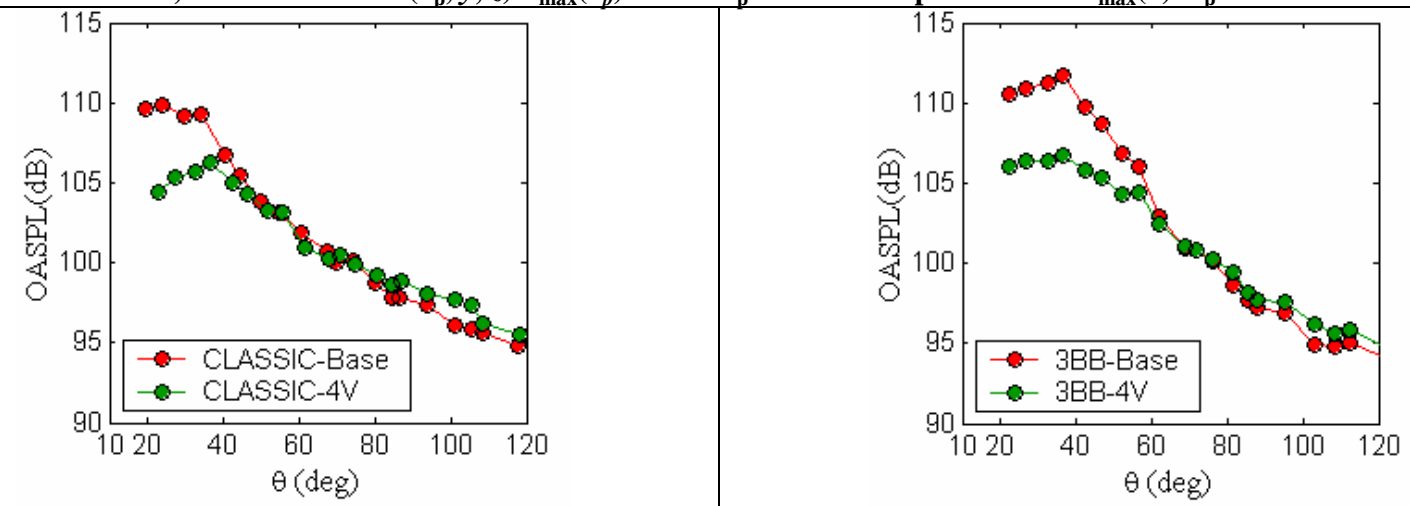

c) Directivity of overall sound pressure level.

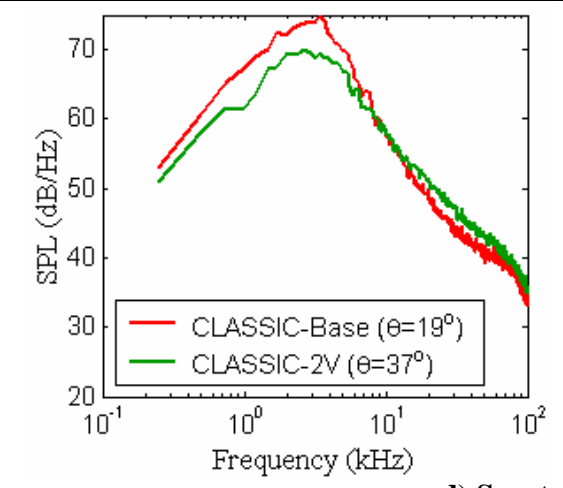

d) Spectra in directions of peak emission.

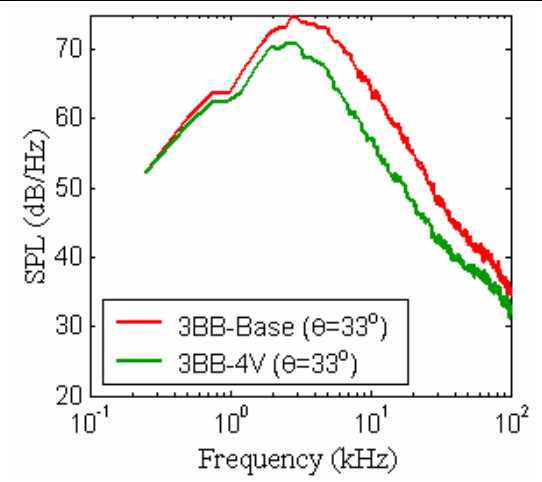

Figure 15. Flow field and acoustics of jets issuing from CLASSIC and 3BB nozzles with two pairs of vanes (4V). Comparison at equal tuning effort. 


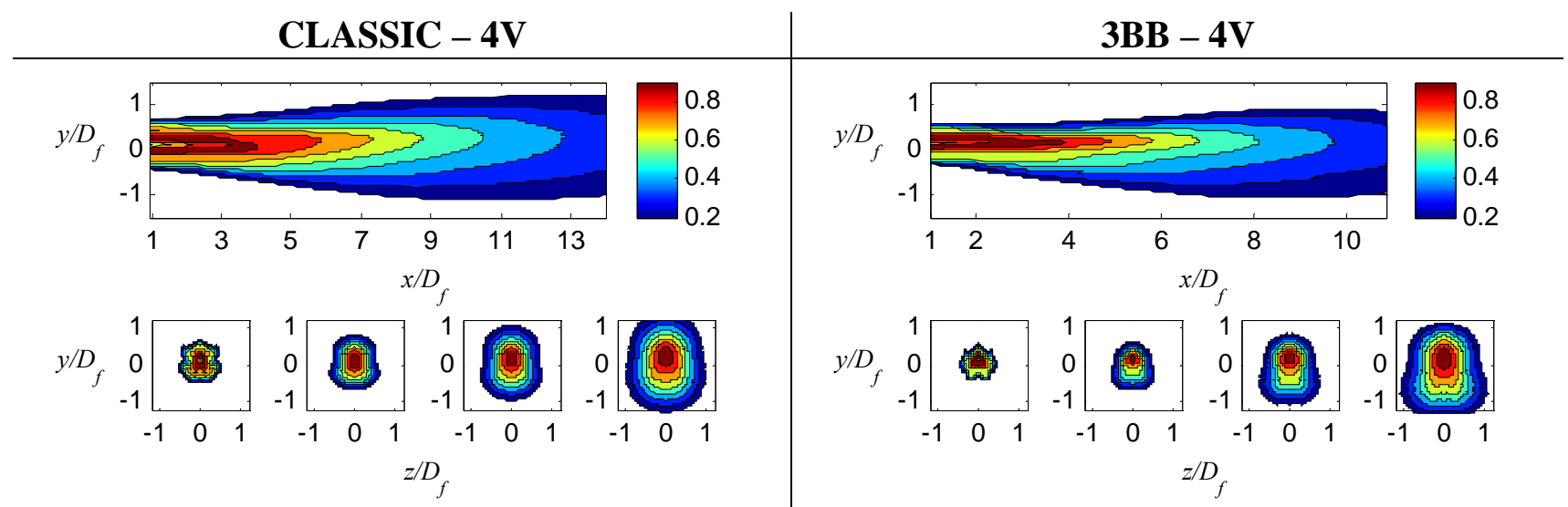

a) Isocontours of $u(x, y, 0) / U_{\mathrm{p}}$ and $\mathrm{u}\left(x_{0}, y, z\right) / u_{\max }(x)$ where $x_{0} / D_{\mathrm{f}}=1,3.5,6,8.5$ from left to right.
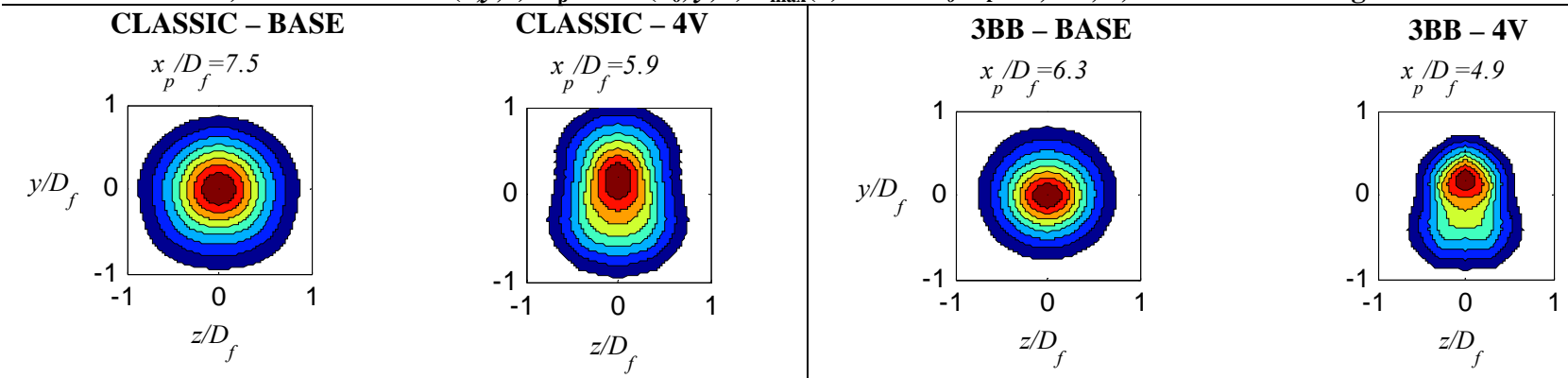

b) Isocontours of $u\left(x_{\mathrm{p}}, y, z\right) / u_{\max }\left(x_{p}\right)$ where $x_{\mathrm{p}}$ denotes the point where $u_{\max }(x) / U_{\mathrm{p}}=0.8$.
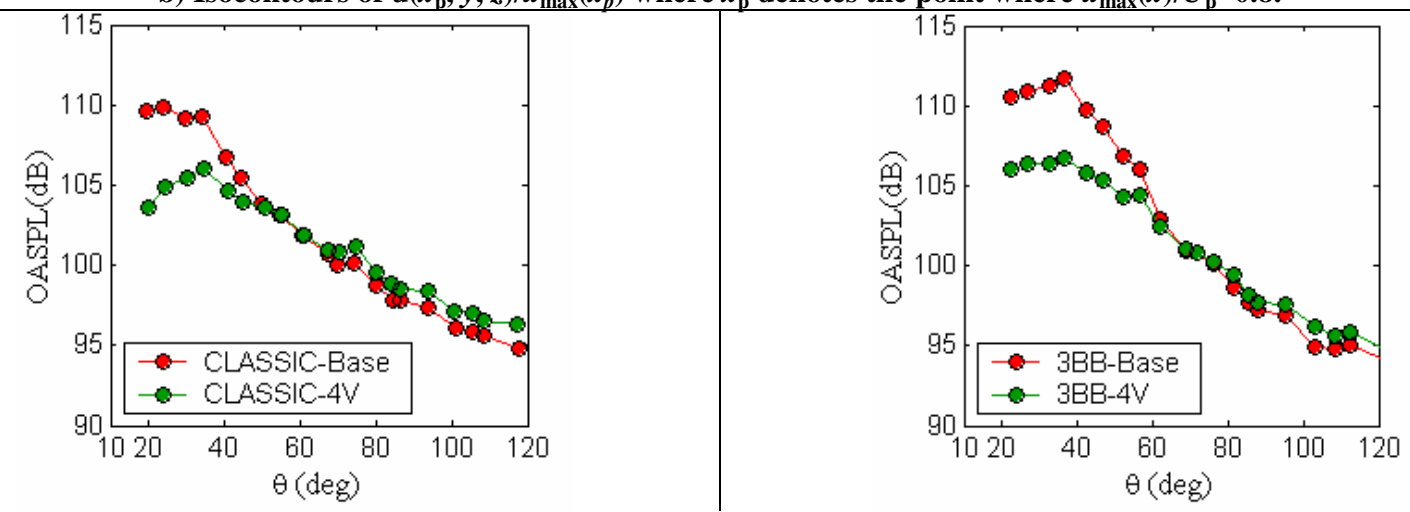

c) Directivity of overall sound pressure level.
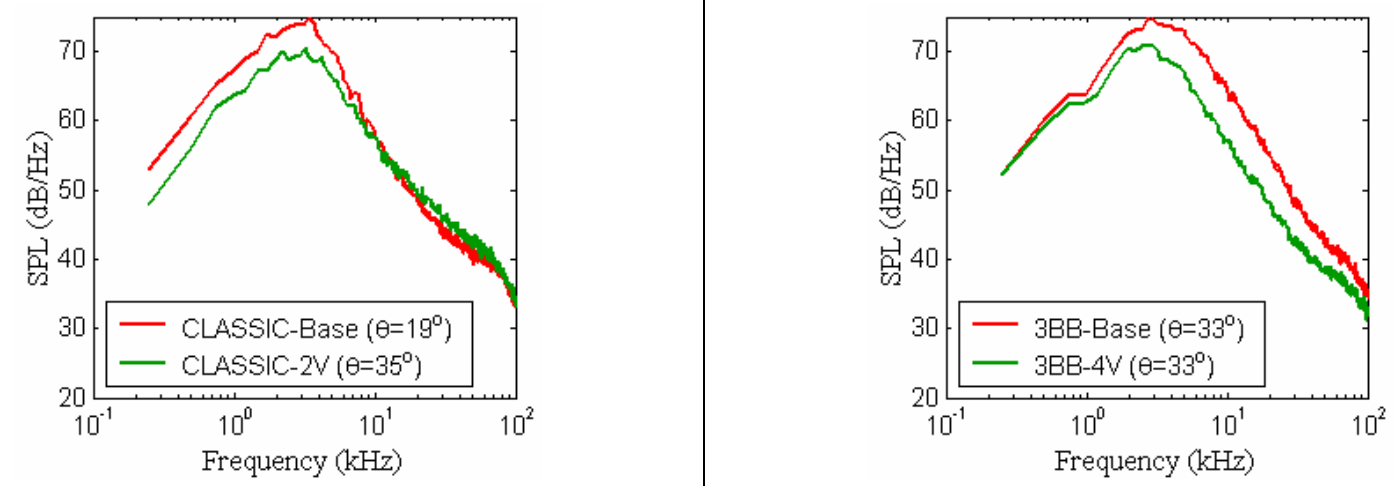

d) Spectra in directions of peak emission.

Figure 16. Flow field and acoustics of jets issuing from CLASSIC and 3BB nozzles with two pairs of vanes (4V). Comparison at equal chord length. 